\title{
Molecular variability in Amerindians: widespread but uneven information*
}

\author{
FRANCISCO M. SALZANO** \\ Departamento de Genética, Instituto de Biociências \\ Universidade Federal do Rio Grande do Sul, Cx. Postal 15053, 91501-970 Porto Alegre, RS \\ Manuscript received on November 6, 2001; accepted for publication on November 13, 2001.
}

\begin{abstract}
A review was made in relation to the molecular variability present in North, Central, and South American Indian populations. It involved results from ancient DNA, mitochondrial DNA in extant populations, HLA and other autosomal markers, $\mathrm{X}$ and $\mathrm{Y}$ chromosome variation, as well as data from parasitic viruses which could show coevolutionary changes. The questions considered were their origin, ways in which the early colonization of the continent took place, types and levels of the variability which developed, peculiarities of the Amerindian evolutionary processes, and eventual genetic heterogeneity which evolved in different geographical areas. Although much information is already available, it is highly heterogeneous in relation to populations and types of genetic systems investigated. Unfortunately, the present trend of favoring essentially applied research suggest that the situation will not basically improve in the future.
\end{abstract}

Key words: amerindians, genetic polymorphisms, population genetic variability, human microevolution.

\section{INTRODUCTION}

Human population genetics has a respectable past of almost 100 years; its root can be placed in the classical papers of Hardy and Weinberg, both published in 1908. In the 1940s and 1950s, the development of the synthetic theory of organic evolution successfully merged genetics with evolutionary biology, establishing the main factors which can be responsible for the intra and interpopulation genetic variability. In a parallel way, researchers interested in human polymorphic (normal, common) genetic markers expressed in blood started to compile and evaluate a vast amount of data at the world level, examples of which are the books by Mourant (1954), Mourant et al. (1958, 1976), Tills et al. (1983),

\footnotetext{
*Invited paper

**Member of Academia Brasileira de Ciências

E-mail: francisco.salzano@ufrgs.br
}

Roychoudhury and Nei (1988), and Cavalli-Sforza et al. (1994).

Amerindians had been fairly well studied during all this period, and relatively recent reviews of their genetic variability and its evolutionary implications were performed by Salzano and CallegariJacques (1988) and Crawford (1998). These last studies, however, had been conducted when the amount of data at the molecular level was still scarce. Therefore, I decided to make a new global evaluation considering the variability in Amerindians that could be disclosed at this level. The results of this endeavor are presented below. Specific questions asked were: 1. From where in Asia did the first American colonizers originate? 2. How many waves of migration occurred, and at what time? 3. Do Amerindians present different levels and types of genetic variability, as compared to other ethnic groups? 4. Are there 
other peculiarities in the evolutionary processes that occurred in these populations? 5. Can significant genetic heterogeneity be found in different regions of the American continent?

\section{ANCIENT DNA}

The year 1984 was a turning point in the genetic study of organic compounds in ancient remains. In that year Higuchi et al. obtained the first successful amplification of ancient DNA (aDNA) from an extinct member of the horse family, the quagga. Soon afterwards, Pääbo (1985) reported the molecular cloning of aDNA from Egyptian mummies. The problem, however, was that at the time large amounts of aDNA were needed for these studies, so that only with the development of the revolutionary technique of polymerase chain reaction (PCR) they received new impetus (review in Herrmann and Hummel 1994).

As far as native Americans are concerned, a large number of papers appeared in succession (Doran et al. 1986, Pääbo et al. 1988, 1989, Pääbo 1989, Hauswirth et al. 1991, 1994, Rogan and Salvo 1994, Merriwether et al. 1994, Handt et al. 1996) emphasizing however many technical problems, especially the inability to amplify a significant number of samples and the contamination of samples with modern DNA (see extensive discussion in Kolman and Tuross 2000). Moreover, practically only mitochondrial DNA (mtDNA) could be obtained. 18S and 28S ribosomal RNA was studied by Rogan and Salvo (1994) from remains of seven individuals from Camarones, Morro, and Azapa, near Arica, northern Chile, but they concluded that the only nucleotide discrepancy observed from the $18 \mathrm{~S}$ consensus could be artifactual. Similarly, dinucleotide markers could not be reliably typed from the remains of 28 individuals (including two Fueguian Indians) by Ramos et al. (1995b).

In a number of instances, however, reproducible results could be obtained for mtDNA, and in Table I 13 series composed of more than 10 individuals, and located all the way from the Aleutian islands to Tierra del Fuego, are presented. A total of 338 individuals had been studied, their remains being dated from 8,000 to 150 years before present. Wide variability in the frequencies of the classical Amerindian mtDNA haplogroups was found, with absence of haplogroups $\mathrm{B}$ and $\mathrm{C}$ among the past Aleuts; extensive intervals within the six USA series (A: 0-31; B: 12-73; C: 0-43; D: 0-55); predominance of the A haplogroup in the Amazon; and absence of A and B among the Dominican Republic and Fueguian-Patagonian remains. Since high frequencies of $\mathrm{C}$ and $\mathrm{D}$ are more common in South America, it is possible that the ancestors of the Taino migrated from South to Central America. The percentages of lineages that could not be classified in these four haplogroups were also quite variable, and reached as high a value as $69 \%$ at the Windower site.

Reports describing less than 10 individuals include: (a) Kolman and Tuross (2000), Plains region, west of USA, five skeletons, two B, two C, one undetermined; (b) Lleonart et al. (1999), Marien 2, Cuba, two skeletons, mother and child, both A; (c) Monsalve et al. (1996), eight Colombian mummies, five A, one B, two C; (d) Rogan and Salvo (1990), two mummies from Camarones, Azapa, Chile who did not present the $9 \mathrm{bp}$ deletion, and therefore were non- B; and (e) Ramos et al. (1995b), bones and teeth from two Fueguian Indians, whose mtDNA was classified as belonging to haplogroups $C$ and D, respectively.

Haplogroup X, that probably occurred in low frequencies among the Asian ancient colonizers of the Americas, has been found also in low prevalences in extanct North, but not South American Indians. As was emphasized by Ribeiro-dos-Santos et al. (1997), however, three of the non A-D haplogroups reported in their 1996 series could be classified as X.

All in all, the expectations that studies in ancient DNA could provide new insights in the Amerindian evolutionary histories have not yet been fulfilled. It is not clear whether the new mtDNA sequences observed in prehistoric skeletons and mummies belong to lineages previously present but now extinct, or are simple methodological artifacts. 


\section{TABLE I}

Frequencies (\%) of the main Amerindian mtDNA haplogroups obtained from ancient DNA material.

\begin{tabular}{l|c|c|c|c|c|c|c|c|c|c}
\hline Archeological site or population & Antiquity & No. indiv. & \multicolumn{3}{|c|}{ mtDNA haplogroups (\%) } & Method & Refer. \\
\cline { 5 - 7 } & $(\mathrm{BP})$ & studied & A & B & C & D & Others & & \\
\hline Aleut, Umnak and other islands & $2,000-4,000$ & 17 & 35 & 0 & 0 & 65 & 0 & & 1 & 1 \\
Pyramid Lake, Great Basin, USA & $300-6,000$ & 19 & 10 & 32 & 0 & 53 & 5 & 1 & 1 \\
Stillwater Marsh, Great Basin, USA & $300-6,000$ & 22 & 5 & 36 & 0 & 55 & 4 & 1 & 1 \\
Great Salt Lake, Fremont, USA & $500-1,500$ & 34 & 0 & 73 & 12 & 6 & 9 & 1 & 1,2 \\
Anazasi, SW USA & $1,010-2,010$ & 22 & 23 & 59 & 9 & 0 & 9 & 1 & 1 \\
Norris Farms Oneota, IL, USA & 700 & 108 & 31 & 12 & 43 & 8 & 6 & 2 & 3 \\
Windower, Central coast, FL, USA & $7,000-8,000$ & 16 & 0 & 12 & 0 & 19 & 69 & 3 & 4 \\
Taino, La Caleta, Dominican Republic & $1,680-670$ & 24 & 0 & 0 & 75 & 25 & 0 & 2 & 5 \\
Amazon Indians, Brazil & $500-4,000$ & 18 & 28 & 6 & 22 & 5 & 39 & 3 & 6 \\
Aónikenk, Chile & 150 & 15 & 0 & 0 & 27 & 73 & 0 & 4 & 7 \\
Kawéskar, Chile & 150 & 19 & 0 & 0 & 16 & 84 & 0 & 4 & 7 \\
Selk'nam, Chile & 150 & 13 & 0 & 0 & 46 & 46 & 8 & 4 & 7 \\
Yámana, Chile & 150 & 11 & 0 & 0 & 91 & 9 & 0 & 4 & 7 \\
\hline
\end{tabular}

Methods: 1. Evaluation of four diagnostic sites, A: Hae III-663; B: 9 bp deletion; C: Hinc II-13259; D: Alu I-5176; 2. Four diagnostic sites plus sequencing; 3. Sequencing; 4 . 9 bp deletion plus sequencing. References: 1. O'Rourke et al. (1996, 2000); 2. Parr et al. (1996); 3. Stone and Stoneking (1993, 1998, 1999); 4. Hauswirth et al. (1994); 5. Laloueza-Fox et al. (2001), 6. Ribeiro-dos-Santos et al. (1996); 7. Lalueza et al. (1993/94, 1997); Lalueza Fox (1996).

\section{MITOCHONDRIAL DNA IN EXTANT POPULATIONS}

Mitochondria are organelles found in the cell's cytoplasm. Their number and form vary depending on the function of the cell; a mammalian liver cell, for instance, harbors around 1,000 to 1,500 mitochondria. They are abundant in oocytes, but in sperm only four mitochondria, formed by the fusion of a larger number, are encountered at the neck of the sperm head; and they do not enter the oocyte at fertilization. Mitochondrial inheritance, therefore, is strictly maternal. Several evidences suggest that they originated as external micro-organisms which developed a symbiotic relationship with their host early in evolution. Their genome has 16,568 base pairs which are arranged in a circular fashion.

The earliest study that could be traced of the mitochondrial DNA (mtDNA) of Amerindians was one by Johnson et al. (1983). Using five restriction enzymes, which can cut the DNA (or not, depending on the nucleotide present in a given region), the types which could be established on this basis were investigated in 200 individuals from six different ethnic extraction, including 30 Warao Indians from Venezuela. The technique used is denominated restriction fragment length polymorphism (RFLP).

One of the co-authors of this paper was Douglas C. Wallace, who, after moving to the Emory University in Atlanta, USA, started a systematic evaluation of these polymorphisms in Amerindians. Initially six restriction enzymes were used (Wallace et al. 1985), but afterwards a set of 14 enzymes was employed (Torroni et al. 1992). Sequencing of the mtDNA control region were also utilized to investigate Amerindian population variability (Ward et al. 1991), and in many of the following papers the two techniques had been used (Torroni et al. 1993 and more recent papers).

Soon it was realized that, depending of the DNA construction in specific sites, the haplotypes (specific arrangements considering different combinations of results) and sequences could be grouped in four main sets (A, B, C, and D haplogroups), that 
would have been present in the earlier colonizers of the Americas. Although this classification has been widely adopted among the researchers in this area, some investigators suggested that additional ones should be considered. For instance, Bailliet et al. (1994) divided each of the four in two subgroups according to whether restriction enzyme Hae III would or would not cut the DNA at position 16517; and the same group of researchers (Bianchi et al. 1995) suggested that not less than 13 founding haplotypes could be distinguished in Amerindians, combining RFLP and sequencing results.

A minor founding lineage, called haplogroup X, was also characterized by Brown et al. (1998). Unlike haplogroups $\mathrm{A}-\mathrm{D}$, haplogroup $\mathrm{X}$ is also found at low frequencies in modern European populations. Although the Amerindian and European variants are distinct, they are however distantly related to each other, and since haplogroup $\mathrm{X}$ has not been unambiguously identified in Asia the authors speculated that it could be an ancient link between Europe/Western Asia and North America. Thus far haplogroup X, although widely found in North American Indians (Smith et al. 1999), was not found in extanct South American natives, although it may have occurred in ancient populations of the region see the previous section on ancient DNA. This problem is presently being extensively considered by our research group (Dornelles et al. 2000).

Since most of the Amerindian studies classified their findings on the basis of the classical four haplogroups, a general survey of the data should inevitably consider them. Table II presents a summary of these findings. A total of 90 samples, including 3,829 individuals, could be assembled. It is well established that Eskimo and Aleut populations arrived much later (4,500 years before present, or BP) than the Amerindians; and people who speak Na-Dene languages may also have arrived later (10,000-8,000 $\mathrm{BP})$ than the remaining Amerindians, who would have crossed the Bering Strait circa 35,000 years BP (review in Crawford 1998; see below a further examination of this question). Therefore, the North American samples have been subdivided in these three sets for the present analysis.

As is shown in Table II, both the Aleut and Eskimo present basically haplogroups A and D. However, although in the only Aleut sample studied D is $2.4 \mathrm{x}$ as frequent as $\mathrm{A}$, the opposite is true among the Eskimo (A 2.5x more common than D). Moreover, among the latter, there is a trend, with higher A frequencies in the north, which decrease as the D prevalences increase at southern latitudes. Among the Na-Dene the most marked characteristic is the high frequency of $\mathrm{A}$, that in the Navajo and Apache occurs in association with lower $B$ numbers. In the North American Amerind both A and D are more prevalent in the north, decreasing at southern latitudes. $\mathrm{B}$ is the most frequent haplogroup, $3.4 \mathrm{x}$ as frequent as D, but the four haplogroups are well represented.

In the Mexican and Central American samples, the majority has an absence of $\mathrm{C}$ and D. A is 1.9x as frequent as $\mathrm{B}$; while in South America the most common haplotype is $\mathrm{B}, 1.7 \mathrm{x}$ as frequent as $\mathrm{A}$. In this region there is a more uniform distribution of the four haplogroups (similarly to what happens in North American Amerinds). No clear geographical clines could be detected.

Mention was already made of divergent views about the number of haplogroups that would be present in the first American colonizers. Other questions that are still being debated today are those related to the number and time of the migration(s) into the Americas. Using measures of mtDNA diversity and other population genetic parameters Bonatto and Salzano (1997a, b) arrived at what they called the "out of Beringia" model of the continent's colonization. The picture suggested is that some time after Beringia had been peopled $(60,000$ to 11,000 years BP) the population expanded and crossed the Alberta ice-free corridor that connected this region to the south of North America or, alternatively, followed a coastal route. The collapse of ice sheets 14,000 to 20,000 years BP isolated Beringia from the rest of the continent during some time (2,000-6,000 years), and it was there that the NaDene and Eskimo diverged biologically. Amerind 


\section{TABLE II}

Summary statistics on the mtDNA haplogroup frequencies observed in Native Americans.

\begin{tabular}{|c|c|c|c|c|c|c|c|c|}
\hline \multirow[t]{2}{*}{ Region and population } & \multirow{2}{*}{$\begin{array}{c}\text { No. of } \\
\text { samples }^{1}\end{array}$} & \multirow{2}{*}{$\begin{array}{l}\text { No. of } \\
\text { indiv. }\end{array}$} & \multirow[t]{2}{*}{ Characteristic } & \multicolumn{5}{|c|}{ mtDNA haplogroup frequencies } \\
\hline & & & & $\mathrm{A}$ & $\mathrm{B}$ & $\mathrm{C}$ & $\mathrm{D}$ & Others \\
\hline \multicolumn{9}{|l|}{ North America } \\
\hline Aleut & 1 & 57 & - & 0.281 & 0 & 0 & 0.667 & 0.052 \\
\hline \multirow[t]{3}{*}{ Eskimo } & 6 & 458 & Minimum & 0.261 & 0 & 0 & 0.033 & 0 \\
\hline & & & Maximum & 0.967 & 0.024 & 0.078 & 0.642 & 0.122 \\
\hline & & & Average & 0.653 & 0.004 & 0.020 & 0.267 & 0.056 \\
\hline \multirow[t]{3}{*}{ Na-Dene } & 4 & 312 & Minimum & 0.517 & 0 & 0 & 0 & 0 \\
\hline & & & Maximum & 0.966 & 0.414 & 0.138 & 0.069 & 0.056 \\
\hline & & & Average & 0.758 & 0.146 & 0.047 & 0.026 & 0.023 \\
\hline \multirow[t]{3}{*}{ Amerind } & 25 & 792 & Minimum & 0 & 0.056 & 0.028 & 0 & 0 \\
\hline & & & Maximum & 0.667 & 0.909 & 0.461 & 0.412 & 0.375 \\
\hline & & & Average & 0.246 & 0.363 & 0.212 & 0.106 & 0.073 \\
\hline \multirow[t]{3}{*}{ Mexico and Central America } & 15 & 440 & Minimum & 0.214 & 0.037 & 0 & 0 & 0 \\
\hline & & & Maximum & 0.850 & 0.714 & 0.484 & 0.259 & 0.062 \\
\hline & & & Average & 0.573 & 0.297 & 0.094 & 0.029 & 0.007 \\
\hline \multirow[t]{3}{*}{ South America } & 39 & 1770 & Minimum & 0 & 0 & 0 & 0 & 0 \\
\hline & & & Maximum & 0.810 & 1.000 & 1.000 & 0.833 & 0.455 \\
\hline & & & Average & 0.188 & 0.318 & 0.234 & 0.233 & 0.027 \\
\hline
\end{tabular}

${ }^{1}$ Only sample sizes of 10 or more individuals were considered. - Sources: Torroni et al. (1992, 1993, 1994); Shields et al. (1993); Horai et al. (1993); Ginther et al. (1993); Santos et al. (1994); Bailliet et al. (1994); Merriwether et al. (1995, 1996, 2000); Batista et al. (1995); Kolman et al. (1995); Bianchi et al. (1995); Lorenz and Smith (1996); Santos (1996); Easton et al. (1996); Ward et al. (1996); Scozzari et al. (1997); Huoponen et al. (1997); Kolman and Bermingham (1997); Rickards et al. (1999); Mesa et al. (2000); Keyeux et al. (2001); unpublished data of S.L. Bonatto, F.M. Salzano et al.

differentiation occurred as the groups that were in North America migrated south. Therefore, there would have been just one major migration wave, which would have started 30,000-40,000 years BP.

An interesting situation is provided by the insertion of 540 bp of the mtDNA's control region into the nuclear genome. All populations studied thus far presented the insertion, suggesting that the event which led to its formation should have occurred after the separation of chimpanzees (which do not have it) and humans, but before the divergence of human populations. Frequency of the insertion is clinal, with low (10\%-28\%) values among Africans, intermediate (36\%-65\%) in Asia, Europe and the Pacific, but very high (54\%-89\%) in four Amerindian groups. This high interpopulation variability, and high heterozygosity levels within popu- lations, make it a valuable tool for the investigation of human variation (Thomas et al. 1996).

Bortolini and Salzano (1996) performed an extensive analysis of the mtDNA variability of Amerindians, comparing it with those of other groups, and reached the following conclusions: (a) Total diversity, either considering characteristic haplogroups or a given set of haplotypes defined by 14 restriction enzymes, is of the same order of magnitude as those observed in other ethnic groups. Moreover, Amerindians present a degree of interpopulation variability that is higher than those found elsewhere; (b) Distinctive features were the low variability of the Na-Dene, and the high interpopulation diversity observed in Central Amerindians; and (c) The total diversity found in A, B, C, and D haplogroups is about one-third of that observed for the 
African L1 and L2 haplogroups, and the share of this variability that is due to the interhaplogroup diversity is much more important $(2 \mathrm{x}$ higher) in Amerindians than in Africans.

\section{AUTOSOME MARKERS - HUMAN LEUKOCYTE ANTIGENS (HLA)}

The HLA system in humans is the genetic region which corresponds, in other vertebrates, to their major histocompatibility complex (MHC). The corresponding antigens play an important role in the regulation of the immune response and can be divided into two groups: class I and class II molecules. Those of class I consist of an $\alpha$ chain and a $\beta 2$ microglobulin, while class II molecules present noncovalently associated $\alpha$ and $\beta$ chains. Both have an extracellular domain, a transmembrane portion, and a cytoplasmic tail.

The function of both sets of molecules is to collect peptide fragments inside the cell and transport them to the cell surface, where the peptide-HLA complex is surveyed by immune system $T$ cells.

HLA variation can be investigated at different levels. In the earlier days the methods were basically serological, but with the advent of the molecular techniques a wide array of procedures were established which range from the study of specific sites by oligonucleotide hybridization to the sequencing of whole regions. As a result the genomic organization of the entire HLA region has been determined (MHC Sequencing Consortium 1999).

The extreme variability of the HLA system, as well as its physiologic importance, stimulated a large number of studies. Examples of evolutionary analyses which tried to establish the factors responsible for this variability are those of Ohta (1998, 2000), Gu and Nei (1999), and Meyer and Thomson (2001). A general evaluation of the population biology of HLA class I molecules, with special emphasis on Native American populations, was provided by Parham and Ohta (1996). As for class II loci, the papers by Erlich et al. (1997), Chen et al. (1999), Monsalve et al. (1999), Salamon et al. (1999), and Valdes et al. (1999) could be consulted. Two im- portant characteristics of the system, not found in other gene complexes, are: (a) the inequivocal evidence of positive selection for several loci; and (b) the widespread generation of variability through interallelic gene conversion.

Previous reviews of the variability of the HLA system in Amerindians have disclosed interesting results. At the serological level Rothhammer et al. (1997), using principal-components analysis and synthetic gene frequency maps, observed longitudinal and latitudinal clines suggesting ancient migration routes. The molecular investigations, on the other hand, indicated: (a) a limited amount of polymorphism compared to other ethnic groups, confirming serological data (for instance, FernándezViña et al. 1997); (b) novel B locus variants, especially in South America (Cadavid and Watkins 1997); (c) the phenomenon of "allele turnover", that is, new alleles tend to supplant older alleles rather than supplementing them (Parham et al. 1997); and (d) an antigen-driven evolution of HLAB molecules of Central and South American Indians aimed at generating novel peptide specificities not provided by the limited repertoire of founder allotypes postulated to have been present in the first migrants to the continent (Yaguie et al. 2000).

Three regions of HLA class II antigens produce functional antigen-presenting heterodimers; they are denominated DP, DQ, and DR. Each heterodimer is composed by the noncovalent association of two glycopeptide chains, $\alpha$ and $\beta$. For DQ two loci are usually recognized, DQA1 and DQB1. Tables III and IV present the information available on the variability of DPB1, DQA1, DQB1, and DRB1 in 61 Amerindian and Eskimo populations. For the four systems, there is far more information for South America than for Central or North America. The most studied system is DQA1, probably due to its use for forensic purposes. It was much more studied in North America (14 samples) than the other three (2-5 samples only). Three to seven alleles were observed in these surveys; *04 was generally the most common in North America, but not in Central or South America, where the most common allele was, 
in the majority of the cases, $* 03$.

The most polymorphic system was DRB1, the number of alleles observed in the different surveys varying from 4 to 22 (averages in the three continents: 10-16). In this case, the allele that most often was present as the most common in North and South America was $* 1402$, but in three of the six Central American investigations the most frequent allele was *0407.

The number of observed DQB1 alleles varied from 3 to 11 (averages: 5-9); *0301 occurred frequently in all three continents, but in South America an equally prevalent allele was $* 0302$. The latter was the most frequent in four of the six Central American studies. DPB1 also reveals several forms (2-12 alleles). In this case $* 0402$ was the variant most often observed as the most frequent in the three regions.

Table $\mathrm{V}$ lists the class I A, B, and C variants which were discovered in Amerindians and are restricted to this ethnic group or derived populations. Locus B is by far the most variable (39 variants found there, against seven for the $\mathrm{A}$ and one for the $\mathrm{C}$ loci). Only a minority of them have arisen through point mutations (just four in 39 , or $10 \%$ for the B locus, proportionally more for the other two), the vast majority having been formed through interlocus recombination or gene conversion. In terms of specificities or subtypes, variants of $* 02$ were the most common in the A locus (5 in 7 or $71 \%$ ), while B variants occurred in seven subtypes; *35 with 14 and $* 39$ with nine accounted for more than half $(59 \%)$ of the 39 B Amerindian mutations. The variants occurred most commonly in South America, where they were detected in 18 tribes or populations living in six countries (Venezuela, Colombia, Ecuador, Brazil, Argentina and Chile). Outside of South America, they were found in three identified groups from Mexico, one from Panama, and one from USA.

\section{OTHER AUTOSOME MARKERS}

There are at least five classes of genetic systems which can be investigated using molecular techniques, namely: (a) Short (for instance, Alu) or large (LINE) insertion polymorphisms; (b) Restriction fragment length polymorphisms (RFLPs); (c) Short tandem repeats (STRs), or microsatellites; (d) Single nucleotide polymorphisms (SNPs); and (e) Variable number of tandem repeats (VNTRs), also called minisatellites. On the other hand, our species possess twenty-two autosome chromosomes, and the number of Amerindian populations which can be studied is large. Unless a kind of global world project is developed to uniformly study a given set of populations with a standardized number of systems, heterogeneity of information is inevitable. It is, therefore, regrettable that the Human Genome Diversity Project received such a strong criticism of political activists that it could not develop appropriately.

Table VI presents the autosome DNA information available for Amerindians. There is no need to emphasize its heterogeneity. While some populations received considerable attention, the data from others are scanty. As was true for the other sets of data previously considered, geographical coverage is also uneven. Thus, while the table lists results concerning 58 South American samples, the numbers for North and Central America are respectively 26 and 7 only. They had been studied with different depth. The most studied North American groups were the Cheyenne, Maya and Navajo, while for the Mazatecan and Zuni populations information is available for one genetic system only.

Similar heterogeneity can be found in Central and South America (Table VI). Cabecar was the most studied group among the Central Amerindians, while the Suruí and Karitiana were the most thoroughly investigated in the south. The Arara, Gavião, Parakanã, Wai Wai, Xavante, and Zoró were also extensively studied in South America, although sometimes with different systems of markers.

It is impossible, here, to provide even a superficial global evaluation of all these populations and markers. Therefore, I will concentrate in some of the most recent reviews in which the Amerindians had been compared with other continental groups, giving also some examples of our own research. 
TABLE III

Results concerning four Class II HLA polymorphisms in 61 Amerindian and Eskimo populations.

\begin{tabular}{|c|c|c|c|c|c|c|c|c|c|c|}
\hline \multirow[b]{2}{*}{$\begin{array}{l}\text { Population and } \\
\text { region }\end{array}$} & \multirow[b]{2}{*}{$\begin{array}{c}\text { No. } \\
\text { of } \\
\text { indiv. }^{1}\end{array}$} & \multicolumn{2}{|c|}{ DPB1 } & \multicolumn{2}{|c|}{ DQA1 } & \multicolumn{2}{|c|}{ DQB1 } & \multicolumn{2}{|c|}{ DRB1 } & \multirow[b]{2}{*}{ Refer. $^{2}$} \\
\hline & & $\begin{array}{c}\text { No. } \\
\text { alleles }\end{array}$ & $\begin{array}{c}\text { Most } \\
\text { common } \\
(\%)\end{array}$ & $\begin{array}{c}\text { No. } \\
\text { alleles }\end{array}$ & $\begin{array}{c}\text { Most } \\
\text { common } \\
(\%)\end{array}$ & $\begin{array}{c}\text { No. } \\
\text { alleles }\end{array}$ & $\begin{array}{c}\text { Most } \\
\text { common } \\
(\%)\end{array}$ & $\begin{array}{c}\text { No. } \\
\text { alleles }\end{array}$ & $\begin{array}{c}\text { Most } \\
\text { common } \\
(\%)\end{array}$ & \\
\hline \multicolumn{11}{|l|}{ North America } \\
\hline N.A. Indians 1 & 46 & 10 & $\begin{array}{c}* 0402 \\
(30)\end{array}$ & 7 & $\begin{array}{l}* 03 \\
(37)\end{array}$ & 10 & $\begin{array}{c}* 0301 \\
(34)\end{array}$ & 20 & $\begin{array}{c}* 0407 \\
(23)\end{array}$ & 3 \\
\hline N.A. Indians 2 & 199 & ND & ND & 6 & $\begin{array}{l}* 03 \\
(38)\end{array}$ & ND & $\mathrm{ND}$ & ND & $\mathrm{ND}$ & 15 \\
\hline Eskimo, Greenland & 42 & ND & ND & 5 & $\begin{array}{c}* 04 \\
49\end{array}$ & ND & ND & ND & ND & 15 \\
\hline Eskimo, USA 1 & 103 & ND & ND & 4 & $\begin{array}{l}* 04 \\
(60)\end{array}$ & ND & ND & ND & ND & 15 \\
\hline Eskimo, USA 2 & 97 & ND & ND & 6 & $\begin{array}{l}* 04 \\
(43)\end{array}$ & ND & ND & ND & ND & 15 \\
\hline Penutian & 26 & ND & ND & ND & ND & ND & ND & 18 & $\begin{array}{l}* 1402 \\
(35)\end{array}$ & 22 \\
\hline Athabascan & 62 & ND & ND & 5 & $\begin{array}{c}* 0501 \\
(48)\end{array}$ & 7 & $\begin{array}{c}* 0301 \\
(45)\end{array}$ & 15 & $\begin{array}{c}* 1402 \\
(35)\end{array}$ & 22 \\
\hline Tlingit 1 & 53 & ND & ND & 9 & $\begin{array}{c}* 0501 \\
(59)\end{array}$ & 10 & $\begin{array}{c}* 0301 \\
(65)\end{array}$ & 16 & $\begin{array}{c}* 1402 \\
(52)\end{array}$ & 1 \\
\hline Tlingit 2 & 62 & ND & ND & 6 & $\begin{array}{l}* 04 \\
(71)\end{array}$ & ND & ND & ND & ND & 15 \\
\hline Sioux 1 & 79 & ND & ND & 6 & $\begin{array}{l}* 03 \\
(49)\end{array}$ & ND & ND & ND & ND & 15 \\
\hline Sioux 2 & 100 & ND & ND & 6 & $\begin{array}{l}* 03 \\
(50)\end{array}$ & ND & ND & ND & ND & 15 \\
\hline Pueblo & 103 & ND & ND & 6 & $\begin{array}{l}* 04 \\
(76)\end{array}$ & ND & ND & ND & ND & 15 \\
\hline Navajo 1 & 81 & ND & ND & 5 & $\begin{array}{l}* 04 \\
(71)\end{array}$ & ND & ND & ND & ND & 15 \\
\hline Navajo 2 & 74 & ND & ND & 4 & $\begin{array}{l}* 04 \\
(77)\end{array}$ & ND & ND & ND & ND & 15 \\
\hline Zuni & 50 & 4 & $\begin{array}{c}* 0402 \\
(61)\end{array}$ & 3 & $\begin{array}{l}* 04 \\
(77)\end{array}$ & ND & ND & 9 & $\begin{array}{c}* 1402 \\
(32)\end{array}$ & 1,15 \\
\hline \multicolumn{11}{|l|}{ Central America } \\
\hline Seri & 100 & ND & ND & 5 & $\begin{array}{c}* 0301 \\
(45)\end{array}$ & 5 & $\begin{array}{c}* 0302 \\
(45)\end{array}$ & 7 & $\begin{array}{c}* 0407 \\
(44)\end{array}$ & 16 \\
\hline Mazatecan & 71 & ND & ND & 7 & $\begin{array}{c}* 03011 \\
(48)\end{array}$ & 7 & $\begin{array}{c}* 0302 \\
(48)\end{array}$ & 15 & $\begin{array}{c}* 0407 \\
(28)\end{array}$ & 24 \\
\hline Zapoteco & 75 & 12 & $\begin{array}{c}* 0402 \\
(70)\end{array}$ & 6 & $\begin{array}{c}* 0301 \\
(38)\end{array}$ & 11 & $\begin{array}{c}* 0301 \\
(32)\end{array}$ & 15 & $\begin{array}{c}* 0802 \\
(22)\end{array}$ & 16 \\
\hline Mixe & 55 & 5 & $\begin{array}{c}* 0402 \\
(91)\end{array}$ & 4 & $\begin{array}{c}* 0501 \\
(44)\end{array}$ & 5 & $\begin{array}{c}* 0301 \\
(41)\end{array}$ & 9 & $\begin{array}{c}* 1602 \\
(31)\end{array}$ & 16 \\
\hline
\end{tabular}


TABLE III (continuation)

\begin{tabular}{|c|c|c|c|c|c|c|c|c|c|c|}
\hline \multirow[b]{2}{*}{$\begin{array}{l}\text { Population and } \\
\text { region }\end{array}$} & \multirow[b]{2}{*}{$\begin{array}{c}\text { No. } \\
\text { of } \\
\text { indiv. }^{1}\end{array}$} & \multicolumn{2}{|c|}{ DPB1 } & \multicolumn{2}{|c|}{ DQA1 } & \multicolumn{2}{|c|}{ DQB1 } & \multicolumn{2}{|c|}{ DRB1 } & \multirow[b]{2}{*}{ Refer. $^{2}$} \\
\hline & & $\begin{array}{l}\text { No. } \\
\text { alleles }\end{array}$ & $\begin{array}{c}\text { Most } \\
\text { common } \\
(\%)\end{array}$ & $\begin{array}{l}\text { No. } \\
\text { alleles }\end{array}$ & $\begin{array}{c}\text { Most } \\
\text { common } \\
(\%)\end{array}$ & $\begin{array}{l}\text { No. } \\
\text { alleles }\end{array}$ & $\begin{array}{c}\text { Most } \\
\text { common } \\
(\%)\end{array}$ & $\begin{array}{l}\text { No. } \\
\text { alleles }\end{array}$ & $\begin{array}{c}\text { Most } \\
\text { common } \\
(\%)\end{array}$ & \\
\hline Mixteco & 103 & 10 & $\begin{array}{c}* 0402 \\
(75)\end{array}$ & 5 & $\begin{array}{c}* 0301 \\
(40)\end{array}$ & 10 & $\begin{array}{c}* 0302 \\
(34)\end{array}$ & 15 & $\begin{array}{c}* 0407 \\
(29)\end{array}$ & 16 \\
\hline Lacandon & 162 & ND & ND & 4 & $\begin{array}{l}* 03 \\
(76)\end{array}$ & 4 & $\begin{array}{c}* 0302 \\
(77)\end{array}$ & 10 & $\begin{array}{c}* 0411 \\
(47)\end{array}$ & 11 \\
\hline \multicolumn{11}{|l|}{ South America } \\
\hline Yukpa & 73 & ND & ND & 3 & $\begin{array}{c}* 0301 \\
(77)\end{array}$ & 3 & $\begin{array}{c}* 0302 \\
(76)\end{array}$ & 6 & $\begin{array}{c}* 0411 \\
(62)\end{array}$ & 16 \\
\hline Bari & 58 & ND & ND & 3 & $\begin{array}{l}* 03 \\
(58)\end{array}$ & 3 & $\begin{array}{c}* 0302 \\
(58)\end{array}$ & 6 & $\begin{array}{c}* 1602 \\
(40)\end{array}$ & $4,8,11$ \\
\hline Warao & 72 & ND & ND & 3 & $\begin{array}{c}* 0501 \\
(64)\end{array}$ & 3 & $\begin{array}{c}* 0301 \\
(64)\end{array}$ & 4 & $\begin{array}{c}* 1602 \\
(37)\end{array}$ & 11 \\
\hline Guahibo & 54 & 6 & $\begin{array}{c}* 0402 \\
(82)\end{array}$ & 4 & $\begin{array}{l}* 0501 \\
(78)\end{array}$ & 8 & $\begin{array}{c}* 0301 \\
(78)\end{array}$ & 8 & $\begin{array}{c}* 1402 \\
(41)\end{array}$ & 12 \\
\hline Colombian I.1 & 21 & ND & ND & ND & ND & ND & ND & 11 & $\begin{array}{c}* 0407 \\
(19)\end{array}$ & 13 \\
\hline Colombian I.2 & 217 & 11 & $\begin{array}{c}* 0402 \\
(49)\end{array}$ & 6 & $\begin{array}{c}* 0301 \\
(40)\end{array}$ & 8 & $\begin{array}{c}* 0302 \\
(36)\end{array}$ & 19 & $\begin{array}{c}* 1402 \\
(20)\end{array}$ & 17 \\
\hline Wayuu 1 & 54 & 3 & $\begin{array}{l}* 1401 \\
(57)\end{array}$ & ND & ND & ND & ND & ND & ND & 10 \\
\hline Wayuu 2 & 56 & ND & ND & 7 & $\begin{array}{l}* 03 \\
(45)\end{array}$ & 9 & $\begin{array}{c}* 0302 \\
(42)\end{array}$ & 20 & $\begin{array}{c}* 1602 \\
(14)\end{array}$ & 6 \\
\hline Wayuu 3 & 52 & ND & ND & ND & ND & 7 & $\begin{array}{c}* 0302 \\
(48)\end{array}$ & 10 & $\begin{array}{c}* 0411 \\
(27)\end{array}$ & 16 \\
\hline Arsario 1 & 50 & 2 & $\begin{array}{l}* 1401 \\
(73)\end{array}$ & ND & ND & ND & ND & ND & ND & 10 \\
\hline Arsario 2 & 10 & ND & ND & 3 & $\begin{array}{l}* 03 \\
(50)\end{array}$ & 3 & $\begin{array}{c}* 0302 \\
(50)\end{array}$ & 4 & $\begin{array}{c}* 0407 \\
(45)\end{array}$ & 6 \\
\hline Ijka 1 & 60 & 6 & $\begin{array}{c}* 0402 \\
(57)\end{array}$ & 6 & $\begin{array}{c}* 0401 \\
(63)\end{array}$ & 6 & $\begin{array}{c}* 0402 \\
(63)\end{array}$ & 10 & $\begin{array}{c}* 0802 \\
(62)\end{array}$ & 12 \\
\hline Ijka 2 & 62 & ND & ND & 7 & $\begin{array}{l}* 03 \\
(45)\end{array}$ & 8 & $\begin{array}{c}* 0402 \\
(41)\end{array}$ & 14 & $\begin{array}{c}* 0802 \\
(41)\end{array}$ & 6 \\
\hline Kogui 1 & 60 & 3 & $\begin{array}{c}* 1401 \\
(45)\end{array}$ & 3 & $\begin{array}{l}* 03 \\
(72)\end{array}$ & 3 & $\begin{array}{c}* 0302 \\
(72)\end{array}$ & 4 & $\begin{array}{c}* 1402 \\
(17)\end{array}$ & 13 \\
\hline Kogui 2 & 34 & ND & ND & 4 & $\begin{array}{l}* 03 \\
(67)\end{array}$ & 4 & $\begin{array}{c}* 0302 \\
(63)\end{array}$ & 6 & $\begin{array}{c}* 0407 \\
(55)\end{array}$ & 6 \\
\hline Tule & 58 & 4 & $\begin{array}{c}* 0402 \\
(53)\end{array}$ & 4 & $\begin{array}{l}* 03 \\
(66)\end{array}$ & 4 & $\begin{array}{c}* 0301 \\
(41)\end{array}$ & 10 & $\begin{array}{c}* 1402 \\
(26)\end{array}$ & 12 \\
\hline Sikuani & 60 & 4 & $\begin{array}{c}* 1401 \\
(37)\end{array}$ & 3 & $\begin{array}{l}* 03 \\
(75)\end{array}$ & 4 & $\begin{array}{c}* 0302 \\
(78)\end{array}$ & 5 & $\begin{array}{c}* 0411 \\
(47)\end{array}$ & 12 \\
\hline Waunana & 60 & 5 & $\begin{array}{c}* 0402 \\
(55)\end{array}$ & 3 & $\begin{array}{c}* 0501 \\
(62)\end{array}$ & 4 & $\begin{array}{c}* 0301 \\
(62)\end{array}$ & 9 & $\begin{array}{c}* 1602 \\
(33)\end{array}$ & 12 \\
\hline
\end{tabular}


TABLE III (continuation)

\begin{tabular}{|c|c|c|c|c|c|c|c|c|c|c|}
\hline \multirow[b]{2}{*}{$\begin{array}{l}\text { Population and } \\
\text { region }\end{array}$} & \multirow[b]{2}{*}{$\begin{array}{c}\text { No. } \\
\text { of } \\
\text { indiv. }^{1}\end{array}$} & \multicolumn{2}{|c|}{ DPB1 } & \multicolumn{2}{|c|}{ DQA1 } & \multicolumn{2}{|c|}{ DQB1 } & \multicolumn{2}{|c|}{ DRB1 } & \multirow[b]{2}{*}{ Refer. $^{2}$} \\
\hline & & $\begin{array}{c}\text { No. } \\
\text { alleles }\end{array}$ & $\begin{array}{c}\text { Most } \\
\text { common } \\
(\%)\end{array}$ & $\begin{array}{c}\text { No. } \\
\text { alleles }\end{array}$ & $\begin{array}{c}\text { Most } \\
\text { common } \\
(\%)\end{array}$ & $\begin{array}{c}\text { No. } \\
\text { alleles }\end{array}$ & $\begin{array}{c}\text { Most } \\
\text { common } \\
(\%)\end{array}$ & $\begin{array}{c}\text { No. } \\
\text { alleles }\end{array}$ & $\begin{array}{c}\text { Most } \\
\text { common } \\
(\%)\end{array}$ & \\
\hline Embera & 40 & 5 & $\begin{array}{c}* 1301 \\
(35)\end{array}$ & 3 & $\begin{array}{l}* 0501 \\
(56)\end{array}$ & 3 & $\begin{array}{c}* 0301 \\
(58)\end{array}$ & 9 & $\begin{array}{c}* 1602 \\
(33)\end{array}$ & 1,2 \\
\hline Nukak & 40 & 3 & $\begin{array}{c}* 0301 \\
(18)\end{array}$ & 3 & $\begin{array}{l}* 0501 \\
(73)\end{array}$ & 3 & $\begin{array}{c}* 0301 \\
(73)\end{array}$ & 5 & $\begin{array}{c}* 1402 \\
(65)\end{array}$ & 12 \\
\hline Vaupes & 46 & 2 & $\begin{array}{c}* 0402 \\
(89)\end{array}$ & ND & ND & ND & ND & ND & ND & 10 \\
\hline Coreguaje & 45 & 2 & $\begin{array}{l}* 1401 \\
(52)\end{array}$ & ND & ND & ND & ND & ND & ND & 10 \\
\hline Ingano & 22 & 5 & $\begin{array}{c}* 0402 \\
* 1401 \\
(27)\end{array}$ & 3 & $\begin{array}{l}* 03 \\
(59)\end{array}$ & 4 & $\begin{array}{c}* 0302 \\
(55)\end{array}$ & 7 & $\begin{array}{c}* 0802 \\
(36)\end{array}$ & 12 \\
\hline Cayapa & 100 & 6 & $\begin{array}{c}* 1401 \\
(49)\end{array}$ & 3 & $\begin{array}{c}* 0301 \\
(56)\end{array}$ & 4 & $\begin{array}{c}* 0302 \\
(41)\end{array}$ & 13 & $\begin{array}{c}* 0407 \\
(27)\end{array}$ & 5,9 \\
\hline Quechua & 108 & ND & ND & 6 & $\begin{array}{l}* 04 \\
(49)\end{array}$ & ND & ND & ND & ND & 20 \\
\hline Ticuna & 49 & 8 & $\begin{array}{c}* 0402 \\
(43)\end{array}$ & 3 & $\begin{array}{l}* 03 \\
(46)\end{array}$ & 5 & $\begin{array}{c}* 0302 \\
(38)\end{array}$ & 9 & $\begin{array}{c}* 0411 \\
(32)\end{array}$ & 21 \\
\hline Xavante & 74 & 5 & $\begin{array}{c}* 0402 \\
(80)\end{array}$ & 3 & $\begin{array}{l}* 0501 \\
(61)\end{array}$ & 3 & $\begin{array}{c}* 0301 \\
(61)\end{array}$ & 5 & $\begin{array}{c}* 1602 \\
* 1402 \\
(30)\end{array}$ & 3 \\
\hline Terena & 60 & 6 & $\begin{array}{c}* 0402 \\
(47)\end{array}$ & ND & ND & 7 & $\begin{array}{c}* 0301 \\
(58)\end{array}$ & 13 & $\begin{array}{c}* 1602 \\
(27)\end{array}$ & 18 \\
\hline Guarani & 92 & 7 & $\begin{array}{c}* 0402 \\
(44)\end{array}$ & 7 & $\begin{array}{l}* 0501 \\
(54)\end{array}$ & 7 & $\begin{array}{c}* 0301 \\
(53)\end{array}$ & 5 & $\begin{array}{c}* 1602 \\
(38)\end{array}$ & 19,23 \\
\hline Kaingang & 108 & 7 & $\begin{array}{c}* 0402 \\
(54)\end{array}$ & 5 & $\begin{array}{c}* 0401 \\
(51)\end{array}$ & 5 & $\begin{array}{c}* 0402 \\
(51)\end{array}$ & 6 & $\begin{array}{c}* 0802 \\
(50)\end{array}$ & 19,23 \\
\hline Chiriguano & 56 & ND & ND & 6 & $\begin{array}{c}* 0501 \\
(61)\end{array}$ & 8 & $\begin{array}{l}* 0301 \\
(59)\end{array}$ & 18 & $\begin{array}{c}* 1406 \\
(19)\end{array}$ & 16 \\
\hline Mataco & 60 & 5 & $\begin{array}{c}* 0402 \\
(70)\end{array}$ & ND & ND & ND & ND & ND & ND & 2 \\
\hline Wichi 1 & 49 & 7 & $\begin{array}{c}* 0402 \\
(62)\end{array}$ & 6 & $\begin{array}{c}* 0501 \\
(46)\end{array}$ & 7 & $\begin{array}{c}* 0301 \\
(48)\end{array}$ & 11 & $\begin{array}{c}* 1402 \\
(26)\end{array}$ & 3 \\
\hline Wichi 2 & 48 & 6 & $\begin{array}{c}* 0402 \\
(67)\end{array}$ & ND & ND & ND & ND & 7 & $\begin{array}{c}* 1402 \\
(28)\end{array}$ & 14 \\
\hline Toba 1 & 135 & 12 & $\begin{array}{c}* 0402 \\
(60)\end{array}$ & 7 & $\begin{array}{l}* 0501 \\
(41)\end{array}$ & 9 & $\begin{array}{c}* 0301 \\
(39)\end{array}$ & 22 & $\begin{array}{l}* 1406 \\
(24)\end{array}$ & 3 \\
\hline Toba 2 & 124 & 7 & $\begin{array}{c}* 0402 \\
(62)\end{array}$ & ND & ND & ND & ND & 10 & $\begin{array}{c}* 1406 \\
(28)\end{array}$ & 14 \\
\hline Pilagá & 19 & 8 & $\begin{array}{c}* 0402 \\
(36)\end{array}$ & 6 & $\begin{array}{c}* 0501 \\
(41)\end{array}$ & 6 & $\begin{array}{c}* 0301 \\
(36)\end{array}$ & 11 & $\begin{array}{c}* 1406 \\
(27)\end{array}$ & 3 \\
\hline
\end{tabular}


TABLE III (continuation)

\begin{tabular}{l|c|cc|cc|cc|cc|c}
\hline \multirow{2}{*}{$\begin{array}{l}\text { Population and } \\
\text { region }\end{array}$} & $\begin{array}{c}\text { No. } \\
\text { of } \\
\text { indiv. }\end{array}$ & $\begin{array}{c}\text { No. } \\
\text { alleles }\end{array}$ & $\begin{array}{c}\text { Most } \\
\text { common } \\
(\%)\end{array}$ & $\begin{array}{c}\text { No. } \\
\text { alleles }\end{array}$ & $\begin{array}{c}\text { Most } \\
\text { common } \\
(\%)\end{array}$ & $\begin{array}{c}\text { No. } \\
\text { alleles }\end{array}$ & $\begin{array}{c}\text { Most } \\
\text { common } \\
(\%)\end{array}$ & $\begin{array}{c}\text { No. } \\
\text { alleles }\end{array}$ & $\begin{array}{c}\text { Most } \\
\text { common } \\
(\%)\end{array}$ & Refer. $^{2}$ \\
\hline Kolla & 60 & ND & ND & ND & ND & 5 & $* 0302$ & 5 & $* 04$ & 16 \\
Chilean I. & 43 & ND & ND & ND & ND & ND & ND & 15 & $* 1402$ & 13 \\
Huilliche & 40 & ND & ND & ND & ND & ND & ND & 9 & $* 04$ & 16 \\
\end{tabular}

${ }^{1}$ Some variability occurs in the number of individuals sampled for the different loci. The number shown is the highest. $-{ }^{2}$ References: 1. Imanishi et al. (1992); 2. Vullo et al. (1992); 3. Cerna et al. (1993); 4. Guédez et al. (1994); 5. Titus-Trachtenberg et al. (1994); 6. Yunis et al. (1994); 7. Garber et al. (1995); 8. Layrisse et al. (1995); 9. Trachtenberg et al. (1995); 10. Briceno et al. (1996); 11. Olivo et al. (1996); 12. Trachtenberg et al. (1996); 13. Blagitko et al. (1997); 14. Fernández-Viña et al. (1997); 15. Rivas et al. (1997); 16. Petzl-Erler et al. (1997); 17. Trachtenberg et al. (1998); 18. Lazaro et al. (1998); 19. Petzl-Erler (1998); 20. Gené et al. (1998); 21. Mack and Erlich (1998); 22. Monsalve et al. (1998); 23. Sotomaior et al. (1998); 24. Arnaiz-Villena et al. (2000). - Abbreviations: ND: Not determined; I: Indians.

In relation to the reviews, two basic approaches can be followed, one including a large set of markers, while the other concentrates in specific DNA regions. The first approach can be exemplified by three analyses: (a) Zhivotovsky et al. (2000) considered 72 STRs in 14 worldwide populations, which included the Maya, Karitiana, and Suruí. Through a statistical index of population expansion, introduced to detect historical changes in population size, they arrived to the conclusion that the Amerindians expanded their populations relatively late in relation to other continental groups, or that they have grown slowly, experimenting also a population bottleneck; (b) Jin et al.'s (2000) investigation involved 64 dinucleotide microsatellite repeats in 11 populations, including the Maya and Karitiana. Low variability in three parameters was obtained in these two groups, compared to the others; and (c) Deka et al. (1999) studied 23 microsatellite loci in 16 ethnically diverse populations, including the Dogrib, Cabecar and Pehuenche. In this case the coefficient of gene diversity was higher in Amerindians than elsewhere.

Two examples can also be singled out for the characterization of the second approach: (a) Four well-mapped SNPs spanning about $75 \mathrm{~kb}$, two near each end of the phenylalanine hydroxylase $(P A H)$ gene were selected to investigate linkage disequilibrium. A total of 29 populations, including the Karitiana, Suruí, and Ticuna, were studied. Disequilibrium between the opposite ends was significant in Native Americans and in one African population only. Distinctive haplotypes were observed between the Amerindians and other groups, including Eastern Asians (Kidd et al. 2000); and (b) Two STRs and a polymorphic Alu element spanning a 22-kb region of the plasminogen activator, tissuetype (PLAT) gene were considered by Tishkoff et al. (2000). Thirty human populations were surveyed, including the Cheyenne, Karitiana, Maya, Suruí, and Ticuna. In this DNA region the Amerindian pattern is not very different from those of other nonAfrican populations.

The DNA results from our group have primarily concentrated in five tribes, the Tupi-Mondé-speaking Gavião, Suruí, and Zoró living in western Amazonia, the Gê-speaking Xavante of Central Brazil, 
TABLE IV

Summary information of the data of Table III.

\begin{tabular}{|c|c|c|c|}
\hline \multirow{2}{*}{$\begin{array}{l}\text { Sistems and characteristics } \\
\text { considered }\end{array}$} & \multicolumn{3}{|c|}{ Continents } \\
\hline & North America & Central America & South America \\
\hline \multicolumn{4}{|l|}{$D P B 1$} \\
\hline \multicolumn{4}{|l|}{ Sample sizes } \\
\hline No. of samples & 2 & 3 & 26 \\
\hline \multicolumn{4}{|l|}{ No. of individuals } \\
\hline Range & $46-50$ & $55-103$ & $19-217$ \\
\hline Average & 48 & 178 & 69 \\
\hline \multicolumn{4}{|l|}{ No. of alleles } \\
\hline Range & $4-10$ & $5-12$ & $2-12$ \\
\hline Average & 7 & 9 & 6 \\
\hline \multirow{2}{*}{\multicolumn{4}{|c|}{$\begin{array}{l}\text { Most common alleles } \\
\text { (no. of occurrences and average, \%) }\end{array}$}} \\
\hline & & & \\
\hline$* 0301$ & - & - & 1,18 \\
\hline$* 0402$ & 2,45 & 3,79 & 18,58 \\
\hline$* 1301$ & - & - & 1,35 \\
\hline$* 1401$ & - & - & 7,49 \\
\hline \multicolumn{4}{|l|}{$D Q A 1$} \\
\hline \multicolumn{4}{|l|}{ Sample sizes } \\
\hline No. of samples & 14 & 6 & 27 \\
\hline \multicolumn{4}{|l|}{ No. of individuals } \\
\hline Range & $42-199$ & $55-162$ & $10-217$ \\
\hline Average & 82 & 94 & 68 \\
\hline \multicolumn{4}{|l|}{ No. of alleles } \\
\hline Range & $3-9$ & $4-7$ & $3-7$ \\
\hline Average & 6 & 5 & 4 \\
\hline \multirow{2}{*}{\multicolumn{4}{|c|}{$\begin{array}{l}\text { Most common alleles } \\
\text { (no. of occurrences and average, \%) }\end{array}$}} \\
\hline & & & \\
\hline$* 03$ & 4,43 & 5,49 & 13,58 \\
\hline$* 04$ & 8,65 & - & 3,54 \\
\hline$* 05$ & 2,53 & 1,44 & 11,58 \\
\hline \multicolumn{4}{|l|}{$D Q B 1$} \\
\hline \multicolumn{4}{|l|}{ Sample sizes } \\
\hline No. of samples & 3 & 6 & 29 \\
\hline
\end{tabular}


TABLE IV (continuation)

\begin{tabular}{|c|c|c|c|}
\hline \multirow{2}{*}{$\begin{array}{l}\text { Sistems and characteristics } \\
\text { considered }\end{array}$} & \multicolumn{3}{|c|}{ Continents } \\
\hline & North America & Central America & South America \\
\hline \multicolumn{4}{|l|}{ No. of individuals } \\
\hline Range & $46-62$ & $55-162$ & $10-217$ \\
\hline Average & 54 & 94 & 65 \\
\hline \multicolumn{4}{|l|}{ No. of alleles } \\
\hline Range & $7-10$ & $4-11$ & $3-9$ \\
\hline Average & 9 & 7 & 5 \\
\hline \multicolumn{4}{|l|}{ Most common alleles } \\
\hline \multicolumn{4}{|l|}{ (no. of occurrences and average, $\%$ ) } \\
\hline$* 0301$ & 3,48 & 2,36 & 13,56 \\
\hline *0302 & - & 4,51 & 13,54 \\
\hline$* 0402$ & - & - & 3,52 \\
\hline \multicolumn{4}{|l|}{$D R B 1$} \\
\hline \multicolumn{4}{|l|}{ Sample sizes } \\
\hline No. of samples & 5 & 6 & 34 \\
\hline \multicolumn{4}{|l|}{ No. of individuals } \\
\hline Range & $26-62$ & $55-162$ & $10-217$ \\
\hline Average & 47 & 94 & 64 \\
\hline \multicolumn{4}{|l|}{ No. of alleles } \\
\hline Range & $9-20$ & $7-15$ & $4-22$ \\
\hline Average & 16 & 12 & 10 \\
\hline \multirow{2}{*}{\multicolumn{4}{|c|}{$\begin{array}{l}\text { Most common alleles } \\
\text { (no. of occurrences and average, \%) }\end{array}$}} \\
\hline & & & \\
\hline$* 04$ & - & - & 2,34 \\
\hline$* 0407$ & 1,23 & 3,34 & 4,36 \\
\hline$* 0411$ & - & 1,47 & 4,42 \\
\hline *0802 & - & 1,22 & 4,47 \\
\hline$* 1402$ & 4,38 & - & 9,30 \\
\hline *1406 & - & - & 4,24 \\
\hline$* 1602$ & - & 1,31 & 8,31 \\
\hline
\end{tabular}




\section{TABLE V}

Data on HLA A, B and C variants observed in Amerindians.

\begin{tabular}{|c|c|c|c|}
\hline Variants & Population distribution & Molecular/physiologic characteristics & References \\
\hline \multicolumn{4}{|l|}{ Locus A } \\
\hline$* 0204$ & Waorani & $\begin{array}{l}\text { Generated by recombination, probably between } A * 31012 \text { and } \\
A * 2402 \text {, leading to a } \mathrm{G} \text { to } \mathrm{T} \text { substitution at nt } 362 \text {, and to the } \\
\text { aa } \mathrm{R} 97 \mathrm{M} \text { change, exon } 3\end{array}$ & 1,3 \\
\hline$* 0212$ & Kaingang & Conversion from $A * 2402$ involving from two to $63 \mathrm{nt}$ exchange & 21 \\
\hline$* 0217$ & Warao & $\begin{array}{l}\text { Differs from } A * 0204 \text { at nt } 355, \mathrm{G} \text { to } \mathrm{T} \text {, leading to the aa change V95L, } \\
\text { and A to T at nt } 368 \text {, leading to the aa change } \mathrm{Y} 99 \mathrm{~F} \text {, exon } 3\end{array}$ & 14 \\
\hline$* 0219$ & Terena, Toba, Wichi & Differs from $A * 0201$ by $7 \mathrm{nt}$ substitutions and 5 aa changes & 19,26 \\
\hline$* 0222$ & Terena & $\begin{array}{l}\text { Differs from } A * 0201 \text { at nt } 196 \text { ( } \mathrm{G} \text { to T), exon } 3 \text {, leading to the } \\
\text { aa L156W change }\end{array}$ & 26 \\
\hline *6816 & Fueguian Indian & $\begin{array}{l}\text { Differs from } A * 68012 \text { at codon } 151 \text {, A to } \mathrm{T} \text {, exon } 3 \text {, leading to the } \\
\text { aa change } \mathrm{H} 151 \mathrm{~L} \text { and modifications in polarity and size }\end{array}$ & 29 \\
\hline$* 6817$ & Kolla & Differs from $A * 68012$ at nt 419, A to $\mathrm{T}$, leading to the aa change $\mathrm{D} 116 \mathrm{~V}$ & 30 \\
\hline \multicolumn{4}{|c|}{ ( } \\
\hline *0807 & Ticuna, Yucpa & $\begin{array}{l}\text { Differs from } B^{*} 0802 \text { by a } \mathrm{C} \text { to } \mathrm{T} \text { substitution at codon } 57 \text {, } \\
\text { leading to aa change } \mathrm{D} 57 \mathrm{~V}\end{array}$ & 25 \\
\hline$* 1504$ & Guarani, Waorani & Conversion from $B * 51011$ involving 16 to $92 \mathrm{nt}$ exchanges & 3,21 \\
\hline *1505 & "Native North American" & Differs from $B^{*} 6203$ by aa changes E152V and W156L & 5 \\
\hline$* 1507$ & "Native North American" & Differs from $B^{*} 6203$ by aa R97S change & 5 \\
\hline$* 1508$ & "Amerindian" & $\begin{array}{l}\text { Differs from } B^{*} 1501 \text { at three nucleotide positions, leading to } \\
\text { aa E63N and S67F changes }\end{array}$ & 7 \\
\hline$* 1520$ & Kaingang & Recombination from $B^{*} 3501$ involving 404 to 817 nt exchanges & 6,21 \\
\hline *1522 & Bari, Cayapa & $\begin{array}{l}\text { Originated from a recombination between the B } 15 \text { and B } 35 \text { groups of } \\
\text { alleles at the middle of intron } 2\end{array}$ & 11,12 \\
\hline$* 1541$ & Nahua & $\begin{array}{l}\text { Differs from } B^{*} 1501 \text { by two base modifications (TG to CT), } \\
\text { leading to aa change W156L }\end{array}$ & 24 \\
\hline$* 3504$ & Waorani & Generated by recombination, probably between $B * 4801$ and $B * 52012$ & 3 \\
\hline *3505 & Guarani, Kaingang & Conversion from $B * 4002$ or $B * 4801$ involving 17 to $106 \mathrm{nt}$ exchanges & 4,21 \\
\hline *3506 & Kaingang & Conversion from $B * 39011$ involving 8 to $156 \mathrm{nt}$ exchanges & 4,21 \\
\hline *35091 & Mapuche & Differs from $B * 3501$ by three codons of the $\alpha 2$ domain & 16 \\
\hline *35092 & Wichi & Differs from $B * 3504$ by three nucleotide differences & 19 \\
\hline *3510 & Jaidukama & $\begin{array}{l}\text { Differs from } B^{*} 3501 \text { at codon } 63 \text { (A to } \mathrm{G} \text { and } \mathrm{C} \text { to } \mathrm{G} \text { changes), } \\
\text { leading to a } \mathrm{N} 63 \mathrm{E} \text { change at exon } 2 \text {. As a consequence, a neutral } \\
\text { polarity was transformed in a negative charge at this site }\end{array}$ & 9 \\
\hline$* 3511$ & Guarani & Conversion from $B^{*} 1501$ or $B * 51011$, involving 1 to $147 \mathrm{nt}$ exchanges. & 21 \\
\hline *3514 & Nahua & $\begin{array}{l}\text { Differs from } B^{*} 3501 \text { by three base changes, leading to aa V152Q } \\
\text { and L156W modifications }\end{array}$ & 15 \\
\hline$* 3516$ & Nahua & Differs from $B^{*} 3501$ by five-base differences and three aa substitutions & 15 \\
\hline *3517 & Otomi & Differs from $B^{*} 3501$ by three-base differences and two aa substitutions & 18 \\
\hline$* 3518$ & Toba, Pilagá & $\begin{array}{l}\text { Differs from } B^{*} 3509 \text { by two silent base changes and by a } \mathrm{C} \text { to } \mathrm{G} \\
\text { substitutions at codon } 156 \text {, leading to aa change R } 156 \mathrm{~L}\end{array}$ & 19,22 \\
\hline$* 3519$ & Pilagá, Toba, Wichi & $\begin{array}{l}\left.\text { Differs from } B^{*} 3501 \text { in nt } 133(\mathrm{C} \text { to } \mathrm{A}) \text { and } 140 \text { (C to } \mathrm{G}\right) \text {, exon } 2 \text {; } \\
\text { and by aa K } 45 \mathrm{~T} \text { change }\end{array}$ & 19,26 \\
\hline$* 3520$ & Terena & Differs from $B * 3501$ at nt 199 (C to T), exon 2 ; and by aa S67F change & 26 \\
\hline$* 3521$ & Terena & $\begin{array}{l}\text { Differs from } B^{*} 3501 \text { at nt } 184 \text { (A to T) and nt } 240 \text { (C to T), exon } 3 \text {; } \\
\text { and by aa V152E, Y171H modifications }\end{array}$ & 26 \\
\hline
\end{tabular}


TABLE V (continuation)

\begin{tabular}{|c|c|c|c|}
\hline Variants & Population distribution & Molecular/physiologic characteristics & References \\
\hline *39022 & Colombian Indian & $\begin{array}{l}\text { Differs from } B^{*} 39021 \text { by two silent substitutions, an A to } \mathrm{G} \text { change at } \\
\text { nt } 246 \text { and a T to } \mathrm{C} \text { substitution at nt } 1008 \text {, } \\
\text { at exons } 2 \text { and } 6 \text {, respectively }\end{array}$ & 10 \\
\hline *3903 & Kaingang, Waorani & Conversion from $B^{*} 4002$ or $B^{*} 4801$ involving 1 to $70 \mathrm{nt}$ exchanges & 3,21 \\
\hline *3905 & $\begin{array}{l}\text { Cayapa, Jaidukama, } \\
\text { Kaingang, Mazatecan, } \\
\text { Mexican, Toba, Yucpa }\end{array}$ & $\begin{array}{l}\text { Differs from } B * 39011 \text { in codon } 74, \mathrm{G} \text { to } \mathrm{T} \text {, } \\
\text { leading to the aa change } \mathrm{D} 74 \mathrm{Y} \text {, } \\
\text { and a shift in peptide specificity }\end{array}$ & 21,31 \\
\hline *39061, & Bari, Mazatecan & They both differ from $B * 3901$ by five base differences, and one from & \\
\hline *39062 & Otomi, Cayapa & another by a synonymous $\mathrm{C}$ to $\mathrm{T}$ change at codon 99 & 17,23 \\
\hline *3907 & Cayapa & $\begin{array}{l}\text { Differs from all other } B^{*} 39 \text { alleles by an A to } \mathrm{G} \text { change at nt } 69 \\
\text { and a } \mathrm{T} \text { to } \mathrm{C} \text { substitution at nt } 76 \text {, leading to the aa changes } \\
\text { N114D and F116S in exon } 3\end{array}$ & 11 \\
\hline *3909 & Xavante, Warao, Yucpa & $\begin{array}{l}\text { Differs from } B * 3901 \text { by the aa change Y99S. Peptide specificity and } \\
\text { common natural ligands similar to B } 27\end{array}$ & 13,28 \\
\hline *3911 & Kuna & $\begin{array}{l}\text { Differs from } B * 3905 \text { by a } C \text { to } \mathrm{G} \text { substitution at nt } 467 \text {, exon } 3 \text {, } \\
\text { leading to aa change L156R }\end{array}$ & 20 \\
\hline *3912 & Terena & $\begin{array}{l}\text { Differs from } B * 3901 \text { by one synonymous and two } \\
\text { non-synonymous nt substitutions, leading to aa Y } 9 \mathrm{D} \text { and S11A changes }\end{array}$ & 26 \\
\hline$* 4004$ & Guarani & Conversion from $B * 3501$ involving 27 to $114 \mathrm{nt}$ exchanges & $4,8,21$ \\
\hline$* 4005$ & Pima & $\begin{array}{l}\text { Generated by recombination between } B * 4002 \text { and } B * 5102 \text {. } \\
\text { It differs from } B * 4002 \text { by two aa changes, V152E and E163L }\end{array}$ & 2 \\
\hline$* 4009$ & Pilagá, Toba & $\begin{array}{l}\text { Differs from } B * 4002 \text { at nt } 66 \text { ( } \mathrm{T} \text { to } \mathrm{C}) \text { and } 69(\mathrm{G} \text { to } \mathrm{A}) \text {, exon } 3 \text {; } \\
\text { and by aa } \mathrm{Y} 113 \mathrm{H}, \mathrm{D} 114 \mathrm{~N} \text { changes }\end{array}$ & 19,26 \\
\hline *4802 & Waorani & Generated by recombination between $B * 4801$ and $B * 3501$ & 3 \\
\hline$* 4803$ & Pilagá, Toba, Wichi & Differs from $B^{*} 4801$ at nt 20 ( $\mathrm{G}$ to $\mathrm{C}$ ), exon 3 ; and by aa S97R change & 19,26 \\
\hline *5104 & Guarani & Conversion from $B * 3501$ involving 10 to $59 \mathrm{nt}$ exchanges & 4,21 \\
\hline *5110 & Kuna & $\begin{array}{l}\text { Differs from other } B^{*} 51 \text { alleles by a large change } \\
\text { in at least } 216 \text { nucleotides }\end{array}$ & 20 \\
\hline *5113 & Kolla & $\begin{array}{l}\text { Differs from } B * 51011 \text { at nt } 76 \text { (A to } \mathrm{T} \text { ) and } 92 \text { (A to } \mathrm{G} \text { ), exon 3, leading } \\
\text { to a synonymous and a non-synonimous (Y116F) changes }\end{array}$ & 27 \\
\hline $\begin{array}{l}\text { Locus C } \\
* 1503\end{array}$ & Guarani & Point mutation from $C w^{*} 1502$ & 21 \\
\hline
\end{tabular}

References: 1. Castaño and López de Castro (1991); 2. Hildebrand et al. (1992); 3. Watkins et al. (1992); 4. Belich et al. (1992); 5. Choo et al. (1993); 6. Domena et al. (1994); 7. Hildebrand et al. (1994); 8. Adams et al. (1995b); 9. Gómez-Casado et al. (1995); 10. Adams et al. (1995a); 11. Garber et al. (1995); 12. Martinez-Laso et al. (1995); 13. Ramos et al. (1995a); 14. Selvakumar et al. (1995); 15. Vargas-Alarcón et al. (1996a,b); 16. Theiler et al. (1996); 17. Zhao et al. (1996); 18. Vargas-Alarcon et al. (1996c); 19. Fernández-Viña et al. (1997); 20. Iwanaga et al. (1997); 21. Parham et al. (1997); 22. Marcos et al. (1997); 23. Vargas-Alarcón et al. (1997); 24. Olivo-Díaz et al. (1998); 25. Mack and Erlich (1998); 26. Marcos et al. (1999); 27. Scott et al. (1999); 28. Yagüe et al. (1999); 29. Gómez-Casado et al. (2000); 30. Ramon et al. (2000); 31. Yagüe et al. (2000). - Abbreviations: aa: amino acid; nt: nucleotide. 
TABLE VI

Autosome DNA information available for Amerindians.

\begin{tabular}{|c|c|c|}
\hline Population & Systems & References \\
\hline \multicolumn{3}{|l|}{ North America } \\
\hline Alaska Natives & Eight $A l u$ polymorphisms & 1 \\
\hline Canadian Indians & $\mathrm{NAD}(\mathrm{P}) \mathrm{H}$ quinone oxidoreductase & 2 \\
\hline Southwestern American Indians & DRD2 (Ser 311 Cys and Taq 1 RFLPs, intron-2 STR) & 3 \\
\hline USA Native Americans & ADH2, ADH3, 9 STRs, 9VNTRs & 4 \\
\hline Eskimo & $\begin{array}{l}\text { Seven } A l u \text { polymorphisms, three subjected to sequencing, } \\
\text { NAD }(\mathrm{P}) \mathrm{H} \text { quinone oxidoreductase, } \mathrm{V}_{K} \text { A18 }\end{array}$ & 5 \\
\hline Carrier-Sekani & $\begin{array}{l}\text { Angiotensin-converting enzyme (ACE), beta-fibrinogen, } \\
\text { beta-globin ( } 5 \text { RFLPs), beta } 2 \text {-adrenergic receptor }\end{array}$ & 6 \\
\hline Cheyenne & $\begin{array}{l}\text { ALDH2, CD4 STR and Alu deletion, delta ccr, DRD2, } \\
\text { DRD4 VNTR, myotonic dystrophy CTG repeats, PLAT (STR/Alu), } \\
33 \text { dinucleotide loci of chromosome 20, } 257 \text { RFLPs, } 20 \text { STRs }\end{array}$ & 7 \\
\hline Cree (see also Ojibwa) & D21S11, FGA, pyruvate carboxylase, 5 Alu polymorphisms & 8 \\
\hline Dogrib & $\begin{array}{l}\text { APO B 3' HVR, myotonic dystrophy CTG repeats, } 23 \text { STRs, } \\
7 \text { VNTRs, including D } 1 S 80\end{array}$ & 9 \\
\hline Huichol & 4 STRs (CSF1P0, HPRTB, TH01, VWA), 2 VNTRs (APOB, D1S80) & 10 \\
\hline Jemez Pueblo (see also Pueblo) & $\begin{array}{l}\text { CD4 STR and Alu deletion, DRD2, DRD4 VNTR, } \\
\text { myotonic dystrophy CTG repeats, PLAT Alu insertion }\end{array}$ & 11 \\
\hline Maya & $\begin{array}{l}\text { ADH2, ADH3, ALDH2, APOE (sequencing, haplotypes) CCR2-64I, } \\
\text { CD4 STR and Alu deletion, CFTR, DRD2, DRD4 VNTR, HPA, } \\
\text { LINE } 1 \text { (sequencing), mtDNA nuclear insertion, PLAT (STR/Alu), } \\
\text { SDF1-3'A, } 9 \text { Alu polymorphisms, } 30 \text { RFLPs, } 45 \text { dinucleotides, chromosomes }\end{array}$ & \\
\hline & 9,10, and 11, 64 dinucleotides, other chromosomes, 20 tetranucleotides & 12 \\
\hline Mazatecans & APOE (RFLP) & 13 \\
\hline Mic Mac & Pyruvate carboxylase & 14 \\
\hline Mvskoke & $\begin{array}{l}\text { Twenty two Alu polymorphisms, beta-globin ( } 5 \text { RFLPs), DRD4 VNTR, } \\
\text { mtDNA nuclear insertion polymorphism }\end{array}$ & 15 \\
\hline Navajo & $\begin{array}{l}\text { ALDH2, ACE, APO, FXIIIB, PR, PV92 and TPA25 Alu } \\
\text { polymorphisms, } 33 \text { dinucleotide repeat loci }\end{array}$ & 16 \\
\hline Nu-Chah-Nulth & Beta-globin, MTHFR & 17 \\
\hline Ojibwa (see also Cree) & D21S11, HUMFIBRA (FGA), pyruvate carboxylase & 18 \\
\hline Pima & $\begin{array}{l}\text { ALDH2, CD4 STR and } A l u \text { deletion, delta ccr5, DRD2, } \\
\text { DRD4 VNTR, PLAT Alu insertion, } 33 \text { dinucleotide repeat loci, } 20 \text { STRs }\end{array}$ & 19 \\
\hline Pueblo (see also Jemez Pueblo) & Cystic fibrosis (CFTR, 4 mutations), delta ccr5 & 20 \\
\hline Purepecha & 4 STRs (CSF1PO, HPRTB, TH01, VWA), 2 VNTRs (APOB, D1S80) & 10 \\
\hline Salish & D21S11, HUMFIBRA (FGA) & 21 \\
\hline Sioux & ACE, APO, FXIIIB, PR, PV92, TPA25 Alu polymorphisms & 22 \\
\hline Tarahumara & 4 STRs (CSF1 PO, HPRTB, TH01, VWA), 2 VNTRs (APOB, D1S80) & 10 \\
\hline Tlingit & Progesterone receptor $(A l u)$ & 23 \\
\hline Zuni & Cystic fibrosis R1162X mutation, 5 Alu polymorphisms & 24 \\
\hline Central America & & \\
\hline Bribri & FV Leiden, FVHR2, FII20210G>A, MTHFRC $>$ T & 25 \\
\hline Cabecar & Bgl II site, PGK1 locus, myotonic dystrophy CTG repeats, 23 STRs & 26 \\
\hline Chorotega & FV Leiden, FVHR2, FII20210G >A, MTHFRC $>$ T & 25 \\
\hline Emberá (see also South America) & CYP2D6, D6S366, D13S126, CSF1PO, F13A1, FESFPS, PLA2A1, TH01 & 27 \\
\hline Guaymi & Bgl II site, $P G K 1$ locus & 28 \\
\hline Ngawbe & CYP2D6, 5 Alu polymorphisms & 29 \\
\hline Wounan & $\begin{array}{l}\text { D6S366, D13S126, CSF1PO, F13A1, FESFPS, PLA2A1, TH01, } \\
5 \text { Alu polymorphisms }\end{array}$ & 30 \\
\hline
\end{tabular}


TABLE VI (continuation)

\begin{tabular}{|c|c|c|}
\hline Population & Systems & References \\
\hline \multicolumn{3}{|l|}{ South America } \\
\hline Brazilian Indians & Tetrahydrofolate reductase (MTHFR) & 31 \\
\hline Colombian Indians & DRD4 VNTR & 32 \\
\hline South Amerindians & ACE, APO, PV92, TPA25 Alu polymorphisms, 25 microsatellites & 33 \\
\hline Aché & APOB signal peptide, LDLR 3' UTR (sequencing), 12 Alu insertions & 34 \\
\hline Arara & $\begin{array}{l}\text { ABO, APOB 3' HVR, APOE RFLP, beta-globin (6 RFLPs), D1S80, } \\
\text { APOB, D4S43, VW1, VW2, F13A1, D12S67, Factor VIII (6 RFLPs), } \\
\text { Factor IX (8RFLPs), HLA-F 5' UTR microsatellites, platelet HPA-1, } \\
\text { HPA-2, HD, IL5R, SCA1, SCA3, TCRVB67, TCRVDJA, TNFA }\end{array}$ & 35 \\
\hline Arrhuaco & ACE, APO, FXIIIB, PV92, TPA25 Alu polymorphisms & 36 \\
\hline Arsario & C0L1A2, DAT1, D12S67, 9 STRs & 37 \\
\hline Awá-Guajá & $\begin{array}{l}\text { APOB, D1S80, D4S43, D12S67, F13A1, HD, HLA-F, HPA-1, } \\
\text { HPA-2, IL5R, TCRVB87, TCRVDJA, TNFA, SCA1, SCA3, VWF1 }\end{array}$ & 38 \\
\hline Baniwa & APOE, delta ccr5, 5 Alu polymorphisms & 39 \\
\hline Bari & D1S80 & 40 \\
\hline Cayapa & APOB, APOE, COL1A2 (3 RFLPs), MTHFRC>T & 41 \\
\hline Chimila & ACE, $\alpha$-globin 2, APO, FXIIIB, PV92, TPA25 Alu insertions, D1S80 & 42 \\
\hline Choreguaje & COL1A2, DAT-1, D12S67, 9 STRs & 37 \\
\hline Doco & Progesterone receptor (PR) Alu & 23 \\
\hline Emberá (see also Central America) & Beta-globin (5 RFLPs) & 43 \\
\hline Gavião & $\begin{array}{l}\text { APOB (3 RFLPs), APOE/APOC-I/APOC-II, LPL (3 RFLPs), } \\
\text { beta-globin (5 RFLPs), CD4, F13A1, CYP1A1 (2 RFLPs), DRD2, } \\
\text { DRD4, SLC6A3, D1S80, LDLR (5 RFLPs), LDLR 3' UTR (sequencing), } \\
\text { TP53 (2 RFLPs, } 1 \text { duplication), von Willebrand (6 RFLPs) }\end{array}$ & 44 \\
\hline Guambiano & 5 Alu polymorphisms & 45 \\
\hline Guarani & 12 Alu insertions & 46 \\
\hline Guayabero & 5 Alu polymorphisms & 45 \\
\hline Ijka & D12S67, 9 STRs & 47 \\
\hline Inca & 5 Alu polymorphisms & 45 \\
\hline Ingano & Beta-globin (5 RFLPs), 5 Alu polymorphisms & 48 \\
\hline Kaingang & 12 Alu insertions, 20 STRs & 49 \\
\hline Kamsa & Beta-globin (5 RFLPs) & 50 \\
\hline Kanamari & Delta ccr5, 5 Alu polymorphisms & 51 \\
\hline Karitiana & $\begin{array}{l}\text { ACE, APO, FXIIIB, PR, PV92, TPA } 25 \text { Alu polymorphisms, } \\
25 \text { microsatellites, ALDH2, CD4 STR and Alu deletion, } \\
\text { DRD2, DRD4 VNTR, LINE } 1 \text { (sequencing), myotonic dystrophy } \\
\text { CTG repeats, PAH, PLAT (STR/Alu), SDF1-3' A, CCR2-64I, } 64 \\
\text { dinucleotides, } 30 \text { RFLPs, } 72 \text { STRs }\end{array}$ & 52 \\
\hline Kashinawa & Delta ccr5, 5 Alu polymorphisms & 51 \\
\hline Katuena & $\begin{array}{l}\text { APOB, D1S80, DYS43, D12S67, F13A1, HD, HLA-F, IL5R, TCRVB67, } \\
\text { TCRVDJA, TNFA, SCA1, SCA3, VWF1 }\end{array}$ & 53 \\
\hline Kayapo (see also Xikrin) & $\begin{array}{l}\text { ABO, APOB 3' HVR, APOE RFLP, beta-globin (6 RFLPs), D1S80, } \\
\text { APOB, D4S43, F13A1, VWF VNTRs, Factor VIII (6 RFLPs), } \\
\text { Factor IX (8 RFLPs), HLA-F 5' UTR microsatellites, platelet HPA-1, } \\
\text { HPA-2, HD, IL5R, SCA1, SCA3, TCRVB67, TCRVDJA, TNFA }\end{array}$ & 54 \\
\hline Kogui & COL1A2, DAT1, D12S67, 9 STRs, 5 Alu polymorphisms & 55 \\
\hline Macushi & APOE & 56 \\
\hline Makiritare & APOE & 56 \\
\hline Mapuche & $\begin{array}{l}\text { Beta-globin (5 RFLPs), CD4, CSF1P0, CYP1A1, CYP2D6, CYP2E1, } \\
\text { D1S80, D2S44, D6S366, D7S820, D13S317, D16S539, FABP, FES/FPS, } \\
\text { F13A1, HPRTB, RENA-4, TH01, VWA }\end{array}$ & 57 \\
\hline
\end{tabular}


TABLE VI (continuation)

\begin{tabular}{|c|c|c|}
\hline Population & Systems & References \\
\hline Mataco (see also Wichi) & APOB signal peptide, APOE RFLP, D1S80, FMR1 repeats & 58 \\
\hline Paez & 5 Alu polymorphisms & 45 \\
\hline Parakanã & $\begin{array}{l}\text { APOB, D1S80, D4S43, D12S67, F13A1, GSTM1 and GSTT1 deletions, } \\
\text { HD, HLA-F, IL5R, TCRVB67, TCRVDJA, TNFA, SCA1, SCA3, } \\
\text { spectrin alpha chain }\left(\alpha^{L E L Y}\right) \text {, VWF1 }\end{array}$ & 59 \\
\hline Pehuenche & APOB, D1S80, myotonic dystrophy CTG repeats, 23 STRs & 60 \\
\hline Piaroa & CD4, F13A1 STRs & 61 \\
\hline Pilagá & APOB signal peptide & 62 \\
\hline Poturujara & HLA-F 5' UTR microsatellite & 63 \\
\hline Quechua & $\begin{array}{l}\text { ACE, APO, FXIIIB, PLAT, PR, PV92, TPA25 Alu polymorphisms, } \\
\text { beta fibrinogen, beta2-adrenergic receptor, CD4 STR and Alu deletion, } \\
\text { DRD4 VNTR, LINE } 1 \text { (sequencing), mtDNA nuclear insertion polymorphism, } \\
\text { YNZ22, APOB, TH01, VW31A }\end{array}$ & 64 \\
\hline Suruí & $\begin{array}{l}\text { ALDH2, } 5 \text { Alu polymorphisms, APOB (3 RFLPs), } \\
\text { APOE/APOC-I/APOC-II, LPL (3 RFLPs), beta-globin (5 RFLPs), CD4 STR and } \\
\text { Alu deletion, F13A1, CFTR, CYP1A1 (2 RFLPs), D1S80, DRD2, DRD4, SCLCA3, } \\
\text { D16S309 (MS 205) minisatellite, } 64 \text { dinucleotides, LDLR (5 RFLPs), } \\
\text { LDLR 3' UTR (sequencing), } 25 \text { microsatellites, mtDNA nuclear insertion } \\
\text { polymorphism, myotonic dystrophy CTG repeats, PAH, PLAT (STR/Alu), PR (Alu), } \\
\text { 30 RFLPs, SDF1-3' A, CCR2-64I, } 72 \text { STRs, TP53 (2 RFLPs, } 1 \text { duplication), } \\
\text { von Willebrand (6 RFLPs) }\end{array}$ & 65 \\
\hline Tehuelche & $\begin{array}{l}\text { CSF1P0, D6S366, D7S820, D13S317, D16S539, FABP, FES/FPS, F13A1, } \\
\text { HPRTB, RENA-4, TH01, VWA }\end{array}$ & 67 \\
\hline Ticuna & $\begin{array}{l}\text { ALDH2, beta-globin ( } 5 \text { RFLPs), CD4 STR and Alu deletion, delta ccr5, DRD2, } \\
\text { DRD4 VNTR, myotonic dystrophy CTG repeat, PAH, } 6 \text { Alu polymorphisms }\end{array}$ & 66 \\
\hline Toba & APOB signal peptide, 5 Alu polymorphisms & 68 \\
\hline Urubu-Kaapor & $\begin{array}{l}\text { APOB, D1S80, D4S43, D12S67, F13A1, HD, HLA-F 5' UTR, IL5R, TCRVB67, } \\
\text { TCRVDJA, TNFA, SCA1, SCA3, VWF1 }\end{array}$ & 69 \\
\hline Wapishana & APOE & 56 \\
\hline Wayampi & $\begin{array}{l}\text { APOB, APOE, beta-globin (6 RFLPs), D1S80, D4S43, VWF, Factor VIII (6 RFLPs), } \\
\text { Factor IX ( } 8 \text { RFLPs), HPA-1, HPA-2 }\end{array}$ & 70 \\
\hline Wayana-Apalaí & $\begin{array}{l}\text { APOB, APOE, beta-globin (6 RFLPs), D1S80, D4S43, VWF, Factor VIII (6 RFLPs), } \\
\text { Factor IX ( } 8 \text { RFLPs), HPA-1, HPA-2 }\end{array}$ & 70 \\
\hline Wayuu & Beta-globin (5 RFLPs), D12S67, 6 Alu polymorphisms, 9 STRs & 71 \\
\hline Wai Wai & $\begin{array}{l}\text { APOB (3 RFLPs), APOE/APOC-I/APOC-II, LPL (3 RFLPs), beta globin (5 RFLPs), } \\
\text { CD4, F13A1, CYP1A1 (2 RFLPs), D1S80, DRD2, DRD4, SLC6A3, HLA-F 5' UTR, } \\
\text { LDLR (5 RFLPs), LDLR 3' UTR (sequencing), TP53 (2 RFLPs, } 1 \text { duplication), } \\
\text { von Willebrand (6 RFLPs) }\end{array}$ & 72 \\
\hline Wichi (see also Mataco) & $\begin{array}{l}\text { CSF1P0, D6S366, D7S820, D13S317, D16S539, FABP, FES/FPS, F13A1, HPRTB, } \\
\text { RENA-4, TH01, VWA }\end{array}$ & 67 \\
\hline Xavante & $\begin{array}{l}12 \text { Alu insertions, APOB (3 RFLPs), APOE/APOC-I/APOC-II, LPL (3 RFLPs), } \\
\text { beta-globin (5 RFLPs), CD4, F13A1, CYP1A1 (2 RFLPs), D1S80, DRD2, DRD4, } \\
\text { SLC6A3, LDLR (5 RFLPs), LDLR 3' UTR (sequencing), TP53 (2 RFLPs, } \\
1 \text { duplication), von Willebrand (6 RFLPs) }\end{array}$ & 73 \\
\hline Xikrin (see also Kayapo) & D1S80, Fc $\gamma$ IIa, IIIb, HPA & 74 \\
\hline Yanomama & $\begin{array}{l}\text { ABO, ACE Alu, APOA, APOB, APOE, APOH, beta-globin (6 RFLPs), } \\
\text { D1S80, D4S43, VWF, Factor VIII (6 RFLPs), Factor IX (8 RFLPs), HPA-1, } \\
\text { HPA-2, } 4804 \text { LR, } 4815 \text { LR }\end{array}$ & 75 \\
\hline Zenu & Beta-globin (5 RFLPs) & 76 \\
\hline Zoé & $\mathrm{D} 1 \mathrm{~S} 80$ & 77 \\
\hline
\end{tabular}


TABLE VI (continuation)

\begin{tabular}{l|l|c}
\hline Population & Systems & References \\
\hline Zoró & APOB (3 RFLPs), APOE/APOC-I/APOC-II, LPL (3 RFLPs), beta-globin (5 RFLPs), CD4, F13A1, & \\
& $\begin{array}{l}\text { CYP1A1 (2 RFLPs), D1S80, DRD2, DRD4, SLC6A3, LDLR (5 RFLPs), LDLR 3' UTR } \\
\text { (sequencing), TP53 (2 RFLPs, 1 duplication), von Willebrand (6 RFLPs) }\end{array}$ & 78 \\
\hline
\end{tabular}

References: 1. Batzer et al. (1994); Stoneking et al. (1997); Novick et al. (1998); 2. Gaedigk et al. (1998); 3. Goldman et al. (1997); 4. McComb et al. (1996); Buroker et al. (1997); Wall et al. (1997); Guarino et al. (1999); 5. Knight et al. (1996); Juul et al. (1997); Gaedigk et al. (1998); Antúnez-de-Mayolo et al. (1999); York et al. (1999); 6. Rupert et al. (1999a,b, 2000); Mattevi et al. (2000b); 7. Dean et al. (1994); Tishkoff et al. (1996a,b, 1998, 2000); Chang et al. (1996); Urbanek et al. (1996); Kidd et al. (1998); Stephens et al. (1998); Kittles et al. (1999); Peterson et al. (1999); 8. Carbone et al. (1998); Frégeaux et al. (1998); Novick et al. (1998); Luiselli et al. (2001); 9. Chakraborty et al. (1992); Deka et al. (1991, 1994, 1999), Deka and Chakraborty (1999); Destro-Bistrol et al. (2000); 10. Rangel-Villalobos et al. (2000); 11. Chang et al. (1996); Tishkoff et al. (1996a,b, 1998); Kidd et al. (1998); 12. Kidd et al. (1991,1998); Chang et al. (1996); Thomas et al. (1996); Tishkoff et al. (1996a,b, 2000); Pérez-Lezaun et al. (1997a,b); Stoneking et al. (1997); Calafell et al. (1998); Novick et al. (1998); Antúnez-de-Mayolo et al. (1999); Mateu et al. (1999, 2001); Osier et al. (1999); Peterson et al. (1999); Su et al. (1999a); Boissinot et al. (2000); Buchanan et al. (2000); Fullerton et al. (2000); Jin et al. (2000); 13. Gamboa et al. (2000); 14. Carbone et al. (1998); 15. Chang et al. (1996); Thomas et al. (1996); Stoneking et al. (1997); Novick et al. (1998); Buchanan et al. (2000); Mattevi et al. (2000b); 16. Duncan et al. (1996); Urbanek et al. (1996); Novick et al. (1998); Antúnez-de-Mayolo et al. (1999); Peterson et al. (1999); York et al. (1999); 17. Harding et al. (1997); Schneider et al. (1998); 18. Carbone et al. (1998); Frégeaux et al. (1998); Luiselli et al. (2001); 19. Chang et al. (1996); Tishkoff et al. (1996a,b); Urbanek et al. (1996); Kidd et al. (1998); Stephens et al. (1998); Kittles et al. (1999); Peterson et al. (1999); 20 . Mercier et al. (1994); Stephens et al. (1998); 21. Frégeaux et al. (1998); Luiselli et al. (2001); 22. Novick et al. (1998); Antúnez-de-Mayolo et al. (1999); York et al. (1999); 23. Antúnez-de-Mayolo et al. (1999); 24. Kessler et al. (1996); Novick et al. (1998); 25. Herrmann et al. (2001); 26. Azofeifa et al. (1995); Deka and Chakraborty (1999); Deka et al. (1999); 27. Kolman and Bermingham (1997); Jorge et al. (1999); 28. Azofeifa et al. (1995); 29. Novick et al. (1998); Jorge et al. (1999); 30. Kolman and Bermingham (1997); Novick et al. (1998); 31. Schneider et al. (1998); 32. Chang et al. (1996); 33. Bowcock et al. (1994); Nei and Takezaki (1996); 34. Demarchi et al. (1999); Battilana et al. (2002); Fagundes et al. (2002); 35. Franco et al. (1994); Guerreiro et al. (1994); Franco et al. (1996); Zago et al. (1996); Covas et al. (1997); Franco et al. (1997); Marin et al. (1997); Olsson et al. (1998); Santos (1998); Santos et al. (1998); Destro-Bistrol et al. (2000); Ribeiro-dos-Santos et al. (2001); 36. Batzer et al. (1994); Novick et al. (1998); 37. Guarino et al. (1999); Mitchell et al. (1999, 2000a,b); 38. Covas et al. (1997); Santos (1998); Santos et al. (1998); Vallinoto et al. (1998); 39. Leboute et al. (1999); Oliveira (1999); Neel (2000); 40. Duncan et al. (1996); 41. Pepe et al. (1994, 1998); Scacchi et al. (1997); Mitchell et al. (1999); 42. Duncan et al. (1996); Knight et al. (1996); Novick et al. (1998); 43. Mesa et al. (2000); 44. Bevilaqua et al. (1995); Hutz et al. (1997, 1999, 2000); Kaufman et al. (1999); Bogdawa et al. (2000); De Andrade et al. (2000, 2002); Kvitko et al. (2000); Mattevi et al. (2000a); Simon et al. (2000); Gaspar et al. (2001); 45. Novick et al. (1998); 46. Battilana et al. (2002); 47. Guarino et al. (1999); Mitchell et al. (2000b); 48. Novick et al. (1998); Mesa et al. (2000); Shimizu et al. (2001); 49. Di Rienzo et al. (1998); Battilana et al. (2002); 50. Shimizu et al. (2001); 51. Leboute et al. (1999); Oliveira (1999); 52. Kidd et al. (1991, 1998, 2000); Bowcock et al. (1994); Chang et al. (1996); Nei and Takezaki (1996); Tishkoff et al. (1996a,b, 1998, 2000); Pérez-Lezaun et al. (1997a,b); Novick et al. (1998); Antúnez-de-Mayolo et al. (1999); Peterson et al. (1999); Su et al. (1999a); Boissinot et al. (2000); Jin et al. (2000); Zhivotovsky et al. (2000); 53. Santos (1998); Vallinoto et al. (1998); 54. Guerreiro et al. (1994); Franco et al. (1996, 1997); Zago et al. (1996); Covas et al. (1997); Marin et al. (1997); Olsson et al. (1998); Santos (1998); Santos et al. (1998); Destro-Bistrol et al. (2000); 55. Novick et al. (1998); Guarino et al. (1999); Mitchell et al. (1999, 2000a,b); 56. Neel (2000); 57. Ginther et al. (1993); Hutz et al. (1997); Kaufman et al. (1998); Muñoz et al. (1998); Sala et al. (1998, 1999); Satten et al. (2001); 58. Kunst et al. (1996); Hutz et al. (1997); Demarchi et al. (1999); De Andrade et al. (2000); 
TABLE VI (continuation)

References (cont.): 59. Arruda et al. (1998); Bassères et al. (1998); Santos (1998); Santos et al. (1998); 60. Deka et al. (1994, 1999); Deka and Chakraborty (1999); Destro-Bistrol et al. (2000); 61. Vona et al. (1996); 62. Demarchi et al. (1999); 63. Santos et al. (1998); 64. Batzer et al. (1994); Chang et al. (1996); Thomas et al. (1996); Tishkoff et al. (1996a,b); Gené et al. (1998); Novick et al. (1998); Antúnez-de-Mayolo et al. (1999); Rupert et al. (1999a,b, 2000); Boissinot et al. (2000); 65. Kidd et al. (1991, 2000); Bowcock et al. (1994); Bevilaqua et al. (1995); Armour et al. (1996); Chang et al. (1996); Nei and Takezaki (1996); Thomas et al. (1996); Tishkoff et al. (1996a,b, 1998, 2000); Hutz et al. (1997, 1999, 2000); Pérez-Lezaun et al. (1997a,b); Kidd et al. (1998); Calafell et al. (1998, 1999); Novick et al. (1998); Antúnez-de-Mayolo et al. (1999); Kaufman et al. (1999); Mateu et al. (1999, 2001); Peterson et al. (1999); Su et al. (1999); Bogdawa et al. (2000); De Andrade et al. (2000); Jin et al. (2000); Kvitko et al. (2000); Mattevi et al. (2000); Simon et al. (2000); Zhivotovsky et al. (2000); Gaspar et al. (2001); De Andrade et al. (2002); Fagundes et al. (2002); 66. Chang et al. (1996); Tishkoff et al. (1996a,b, 1998, 2000); Kidd et al. (1998, 2000); Leboute et al. (1999); Oliveira (1999); Peterson et al. (1999); Mesa et al. (2000); 67. Sala et al. (1998, 1999); Satten et al. (2001); 68. Novick et al. (1998); Demarchi et al. (1999); 69. Santos (1998); Santos et al. (1998); Vallinoto et al. (1998); 70. Guerreiro et al. (1994); Franco et al. (1996, 1997); Zago et al. (1996); Covas et al. (1997); Marin et al. (1997); Destro-Bistrol et al. (2000); 71. Novick et al. (1998); Antúnez-de-Mayolo et al. (1999); Guarino et al. (1999); Mesa et al. (2000); Mitchell et al. (2000b); Shimizu et al. (2001); 72. Bevilaqua et al. (1995); Hutz et al. (1997, 1999, 2000); Santos et al. (1998); Kaufman et al. (1999); Bogdawa et al. (2000); De Andrade et al. (2000, 2002); Kvitko et al. (2000); Mattevi et al. (2000a); Simon et al. (2000); Gaspar et al. (2001); Fagundes et al. (2002); 73. Bevilaqua et al. (1995); Heidrich et al. (1995); Hutz et al. (1999, 2000); Kaufman et al. (1999); Bogdawa et al. (2000); De Andrade et al. (2000, 2002); Kvitko et al. (2000); Mattevi et al. (2000a); Simon et al. (2000); Gaspar et al. (2001); Battilana et al. (2002); Fagundes et al. (2002); 74. Vallinoto et al. (1998); Chiba et al. (2000); Kuwano et al. (2000); 75. Guerreiro et al. (1992); Crews et al. (1993); Roewer et al. (1993); Barley et al. (1994); Franco et al. (1994, 1996, 1997); Zago et al. (1996); Covas et al. (1997); Marin et al. (1997); Olsson et al. (1998); Destro-Bistrol et al. (2000); Neel (2000); 76. Mesa et al. (2000); 77. Vallinoto et al. (1998); 78. Bevilaqua et al. (1995); Heidrich et al. (1995); Hutz et al. (1999, 2000); Kaufman et al. (1999); Bogdawa et al. (2000); De Andrade et al. (2000, 2002); Kvitko et al. (2000); Mattevi et al. (2000a); Simon et al. (2000); Gaspar et al. (2001); Fagundes et al. (2002).

and the Carib-speaking Wai Wai who live farther north, near the Guiana border. A global analysis performed by Hutz et al. (1999) and involving eight autosomal DNA, mtDNA, and 23 blood group plus protein loci indicated that the autosomal DNA pattern of population relationships was exactly that expected according to history and geography, while the two other sets showed some departures from expectation.

Another type of comparison was made by Battilana et al. (2001), who studied 12 Alu polymorphisms, five of them never studied before in Amerindians, in four South American groups, two of the Tupi (Aché, Guarani) and two (Kaingang, Xavante) of the Gê linguistic families. The intertribal relations obtained with these polymorphisms were essentially the same as those found with 10 blood group + protein systems. The Aché, a Paraguayan tribe that only recently established more permanent contacts with non-Indians, clearly differentiated from the other three, showing, however, somewhat more similarity with the Guarani than with the Gê groups. This finding suggests that they may be a differentiated Guarani population that reverted or remained in the forests, and not a Gê group that preceded the Guarani colonization of Paraguay.

Considering the seven Alu polymorphisms studied by Battilana et al. (2001) for which there is comparative information in other Amerindians, the joint data are presented in Table VII. Again, the information available for South America is much larger than that obtained in North + Central America. Among the latter only TPA25 was studied in more than 500 individuals, while in South America 
this number was reached for five of the seven loci. Average differences between the North + Central as compared to South America are small, in only one case (A25) exceeding the $10 \%$ value.

Fagundes et al. (2001) have sequenced 794 bp from the Alu-rich 3' untranslated region (3'-UTR) of the low density lipoprotein receptor (LDLR) gene from 102 chromosomes of a worldwide sample, about half of them derived from South American Indians. The region under study and its Alu $\mathrm{U}$ (upstream) repeat showed the highest mutation rates $(0.56 \%$ per million years-Myr; $0.90 \% \mathrm{Myr})$ and nucleotide diversity $(0.51 \%$ and $0.92 \%)$ ever found in nuclear sequences. Since the discrepant results obtained considering autosomal, mtDNA and $\mathrm{Y}$ chromosome data in relation to the origin and spread of modern humans may be related to differential rates of variation in these three sets, this region has a strong potential for evolutionary studies. The Amerindian data are compatible with a recent population bottleneck, as was previously suggested by mtDNA and $Y$ chromosome studies, but not by other studies with autosomal DNA.

\section{AND Y CHROMOSOME VARIATION}

Much less studies have been performed in the $\mathrm{X}$ than in the $\mathrm{Y}$ chromosome of Amerindians. As is indicated in Table VIII, while only nine systems had been investigated in the $\mathrm{X}, 66$ were considered in the $\mathrm{Y}$. The number of populations studied is also markedly different (nine for the X; 50 for the Y). As was true for other loci, South America was proportionally better investigated.

There is a simple explanation for the $\mathrm{X} / \mathrm{Y}$ differences. The $\mathrm{Y}$ chromosome provides an unusual opportunity for the investigation of patrilineal lineages free of recombination, to be conveniently compared with the matrilineal lineages derived from the mtDNA. The $X$ chromosome regions, on the other hand, present or exclusive inheritance that however is not free from recombination; or pseudoautosomal patterns in the homologous $\mathrm{X} / \mathrm{Y}$ portion of them. Therefore, the dynamics of the process is not easily ascertainable.
The first Y chromosome findings which suggested almost no or very restricted variability were contradicted by more recent studies which documented more variation, although it is generally less marked than those found in the mtDNA or autosome regions. Several methods had been employed in these investigations, which included short tandem repeats (STRs), biallelic markers, or sequencing. To further complicate the matter, different arrays were utilized by different researchers (see the references in Table VIII), making comparisons among studies difficult.

Despite these shortcomings some generalizations are possible, as evidenced by most recent reviews. For instance, the suggestion of a single founding haplotype for the Americas (see, among others, Bianchi et al. 1997) has been substituted by the notion that at least two Y chromosome lineages contributed to the early peopling of the Americas (Rodriguez-Delfin et al. 1997, Karafet et al. 1999, Ruiz-Linares et al. 1999). As for their origin, Santos et al. (1999) suggested the central Siberian region as their possible parental land.

Bianchi et al. (1998) derived what they considered to be the ancestral founder haplotype, and dated its age as being of 22,770 years, in good agreement with mtDNA estimates. Carvalho-Silva et al. (1999), on the other hand, examined the low variability of the DYS19 microsatellite, as compared to those of five other tetranucleotide repeat loci. Factors such as relative position in the chromosome, base composition of the repeat motif and flanking regions, as well as degree of perfection and size (repeat number) of the variable blocks were considered. The only one that may be related to this low variability is small average number of repeats. Significant differences in variability using other markers were also observed between populations living in the Andean and non-Andean regions of South America (Tarazona-Santos et al. 2001).

Table IX shows data which exemplify the type of results that can be obtained using these markers. Haplotype distributions based on seven loci are presented, for comparisons involving North, Cen- 


\section{TABLE VII}

Characteristics of previous studies involving seven Alu insertions performed in Amerindians.

\begin{tabular}{l|c|c|c|c|c|c|c}
\hline Geographical region and & \multicolumn{7}{|c}{ L o i } \\
\cline { 2 - 8 } statistical characteristics & FXIIIB & MABDI & $A 25$ & TPA25 & $A P O$ & $P V 92$ & $A C E$ \\
\hline North + Central America & & & & & & & \\
$\quad$ No. of samples & 10 & 2 & 2 & 16 & 10 & 10 & 10 \\
No. of individuals & 323 & 101 & 101 & 593 & 323 & 323 & 323 \\
Lowest frequency & 0.50 & 0.45 & 0.21 & 0.29 & 0.90 & 0.57 & 0.44 \\
Highest frequency & 1.00 & 0.46 & 0.21 & 0.66 & 1.00 & 0.99 & 0.89 \\
Average & 0.84 & 0.45 & 0.21 & 0.55 & 0.97 & 0.75 & 0.70 \\
South America & & & & & & & \\
No. of samples & 21 & 8 & 4 & 23 & 23 & 23 & 21 \\
No. of individuals & 840 & 454 & 179 & 810 & 856 & 876 & 695 \\
Lowest frequency & 0.53 & 0.42 & 0.01 & 0.12 & 0.58 & 0.42 & 0.54 \\
Highest frequency & 1.00 & 0.71 & 0.23 & 0.93 & 1.00 & 1.00 & 1.00 \\
Average & 0.90 & 0.54 & 0.07 & 0.55 & 0.97 & 0.86 & 0.78 \\
\hline
\end{tabular}

Sources: Batzer et al. (1994); Barley et al. (1994); Tishkoff et al. (1996); Stoneking et al. (1997); Novick et al. (1998); Oliveira (1999); Rupert et al. (1999); Tishkoff et al.(2000); Battilana et al. (2002).

tral, and South American Indians. Haplotypes 5 to 7 occur in low frequencies, and since they present high prevalences in European or African populations, may be due to interethnic gene flow. The patterns of the other four are however more interesting. Haplotype 1, present in low frequencies in Asia only, is restricted to South America, and more specifically to two tribes of this region (Ticuna and Wayuu). Haplotypes 2 and 3 show opposite north-south gradients, while haplotype 4, common in Asians, has limited frequencies in the Americas.

\section{HUMAN/MICROORGANISM COEVOLUTION}

Several studies tried to relate microorganism variability with past Amerindian migrations. One example is the work of Agostini et al. (1997) on the human polyomavirus JC (JCV). They investigated its excretion in 68 Navaho and 25 Flathead Indians from USA. The large majority were of type $2 \mathrm{~A}$, consistent with the origin of these strains in Asia.

Much more detailed investigations had been conducted with the T-cell lymphotropic virus types I and II (HTLV-I, HTLV-II), especially with the latter. Examples are the papers by Neel et al. (1994), Black (1997), Miura et al. (1997), and Salemi et al. (1999). Since HTLV-II was present in high frequencies in American Indians, but not in Siberian ethnic groups, it was suggested that the first migrants to the New World should have been mainly from Mongolia and Manchuria. On the other hand, two HTLV-II subtypes, $a$ and $b$, have been observed in Amerindians, and curiously, HTLV-IIa was found in Navajo populations of New Mexico and Kayapo groups of Central Brazil, but not in geographically intermediate communities.

\section{OVERVIEW}

It is clear that we presently have an enormous array of tools that could be used for the investigation of evolutionary processes in Amerindians or any other ethnic group. They differ in type of inheritance (lineal, maternal or paternal; recombina- 


\section{TABLE VIII}

Information available on Amerindian X and Y chromosome genetic markers.

\begin{tabular}{|c|c|c|}
\hline Chromosome and systems & Populations & References \\
\hline $\begin{array}{l}\text { X Chromosome } \\
\text { DXS52, DXS548, DXS8174, DXS8175, } \\
\text { DXYS156X, HUMARA [AGC]n, } \\
\text { HUMHPRTB [AGAT]n, X-FRAXAC1, } \\
\text { X-dys44 }\end{array}$ & $\begin{array}{l}\text { North America: Ojibwa, Seminole. } \\
\text { Central America: Emberá, Kuna, Maya, Ngöbé, Wounan. } \\
\text { South America: Aché, Arara, Guahibo, Karitiana, Kayapo, } \\
\text { Wai Wai, Wayampi, Wayana-Apalai, Yanomama. }\end{array}$ & $1-5$ \\
\hline $\begin{array}{l}\text { Y Chromosome } \\
\alpha \mathrm{h}, \text { DXYS156Y, DYS1, DYS11 } \\
\text { DYS19, DYS199, DYS257, DYS271 } \\
\text { DYS287 (YAP), DYS388, DYS389A, } \\
\text { DYS389B, DYS390, DYS391, DYS392, } \\
\text { DYS393, DYS394, DYS395, DYS413, } \\
\text { DYZ3, M3, M5, M7, M9, M15, M17, } \\
\text { M19A, M45, M50, M88, M89, M95, } \\
\text { M103, M110, M111, M119, M120, M122, } \\
\text { M134, M911, polyAYAP, PN1, PN2, } \\
\text { PN3, pSRY373, pY } \alpha 1, \text { RBF5 (T } \rightarrow \text { C) } \\
\text { (Tat), RPS4Y, SRY, SRY1532, SRY4064, } \\
\text { SRY9138, SRY10831, SY81, YCAI, } \\
\text { ICAII, YCAIIIA, YCAIII, 47z, 50f2, 92R7 }\end{array}$ & $\begin{array}{l}\text { North America: Cheyenne, Dogrib, Eskimo, Havasupai, Mvskoke } \\
\text { Navajo, Ojibwa, Pima, Pueblo, Seminole, Sioux, Tanana, Zuni. } \\
\text { Central America: Bribri, Cabecar, Emberá, Guaymi, Huetar, } \\
\text { Kuna, Maya, Mixe, Mixtec, Ngöbé, Teribe, Wounan, Zapotec. } \\
\text { South America: Aché, Arara, Arsario, Atacameño, Auca, } \\
\text { Awá-Guajá, Ayoreo, Bari, Cayapa, Chimila, Chorote, Chulupi, } \\
\text { Cinta Larga, Gavião, Guahibo, Guarani, Huilliche, Ijka, Ingano, } \\
\text { Karitiana, Katuena, Kayapo, Kogui, Krahó, Lengua, Mapuche, } \\
\text { Mocoví, Pacaás Novos, Parakanã, Pehuenche, Quechua, Suruí, } \\
\text { Susque, Tehuelche, Ticuna, Toba, Urubu-Kaapor, } \\
\text { Wai Wai, Warao, Wayampi, Wayana-Apalai, Wayuu, Wichi, } \\
\text { Xavante, Yagua, Yanomama, Yupca, } \\
\text { Zenu, Zoé, Zoró. }\end{array}$ & $1-3,6-40$ \\
\hline
\end{tabular}

References: 1. Zago et al. (1996); 2. Kolman and Bermingham (1997); 3. Scozzari et al. (1997b); 4. Zietkiewicz et al. (1997, 1998); 5. Mingroni-Netto et al. (2002); 6. Roewer et al. (1993); 7. Mathias et al. (1994); 8. Torroni et al. (1994); 9. Jobling and Tyler-Smith (1995); 10. Pena et al. (1995); 11. Santos et al. (1995a,b, 1996a,b,c, 1999); 12. Deka et al. (1996); 13. Hammer and Zegura (1996); 14. Mitchell (1996); 15. Ruiz-Linares et al. (1996, 1999); 16. Underhill et al. (1996, 1997); 17. Bianchi et al. (1997, 1998); 18. Hammer et al. (1997, 1998); 19. Huoponen et al. (1997); 20. Karafet et al. (1997, 1998, 1999); 21. Lell et al. (1997); 22. Rodriguez-Delfin et al. (1997); 23. Scozzari et al. (1997a,b); 24. Sherry and Batzer (1997); 25. Zerjal et al. (1997, 1999); 26. Bianchi et al. (1997, 1998); 27. Ruiz Narvaez (1998); 28. Santos (1998); 29. Carvalho-Silva et al. (1999); 30. Guarino et al. (1999); 31. Kittles et al. (1999); 32. Su et al. (1999b); 33. Vallinoto et al. (1999); 34. Bravi et al. (2000, 2001); 35. Forster et al. (2000); 36. Mesa et al. (2000); 37. Bortolini et al. (2001); 38. Kayser et al. (2001); 39. Ribeiro-dos-Santos et al. (2001); 40. Tarazona-Santos et al. (2001).

tional; based on extinct or extant material; involving not only the human, but also other genomes). Unfortunately, heterogeneity is the rule, not only in relation to the markers used, but also concerning the populations sampled. For instance, South America has been more thoroughly sampled than Central or North America. This may be due to the fact that pop- ulations were more diversified and intermixed less in the south than in northern latitudes. But other factors may be involved. Since field work involving humans is becoming increasingly difficult, and attempts to uniformize the data failed, this situation probably is not going to improve in the near future. Answers to the questions posed in the intro- 


\section{TABLE IX}

Y chromosome seven biallelic haplotype distribution observed in Native Americans ${ }^{1}$.

\begin{tabular}{|c|c|c|c|c|c|}
\hline \multirow[t]{2}{*}{ Characteristics } & \multicolumn{3}{|c|}{ North America } & \multirow{2}{*}{$\begin{array}{l}\text { Central } \\
\text { America }\end{array}$} & \multirow{2}{*}{$\begin{array}{c}\text { South } \\
\text { America }\end{array}$} \\
\hline & Eskimo-Aleut & Na-Dene & Amerind & & \\
\hline No. of samples & 2 & 2 & 4 & 6 & 17 \\
\hline No. of individuals & 66 & 68 & 122 & 110 & 356 \\
\hline $\begin{array}{l}\text { Haplotype frequencies } \\
\text { (averages, per cent) }\end{array}$ & & & & & \\
\hline 1 & 0 & 0 & 0 & 0 & 7 \\
\hline 2 & 45 & 37 & 22 & 80 & 78 \\
\hline 3 & 46 & 51 & 58 & 15 & 11 \\
\hline 4 & 0 & 8 & 7 & 0 & 0 \\
\hline 5 & 9 & 4 & 1 & 3 & 2 \\
\hline 6 & 0 & 0 & 1 & 2 & 1 \\
\hline 7 & 0 & 0 & 1 & 0 & 1 \\
\hline
\end{tabular}

${ }^{1}$ The haplotypes are based in the genetic constitution present in the following sites: M19, DYS199, RPS4Y711, YAP, SY81, M9, 92R7, and were defined as follows: 1. ATC-AGT; 2. TTC-AGT; 3. TCC-AGT; 4. TCT-ACC; 5. TCC-ACC; 6. TCC+ACC; 7. TCC+GCC. - Source: Karafet et al. (1999); Bortolini et al. (2002).

duction can now be tried: 1 . The original homeland of the first Amerindians remains elusive, different results having been obtained using mtDNA, autosomal, sex-chromosome, or viral parasitic information; 2. Different waves of migration had been postulated on the basis of mtDNA, Y chromosome, and other types of genetic and non-genetic (for instance, linguistic) evidences. The suggested dates of their occurrence are also variable; 3 . The level of genetic variability of Amerindians, as compared to other groups, cannot be easily ascertained. There is restriction of variability for some of the mtDNA and HLA markers, but this is not necessarily so for other genetic traits. On the other hand, interpopulation variation seems to be more marked in Amerindians than elsewhere, probably due to their population structure; 4 . The most exciting differences between Amerindians and non-Amerindians are those related to the HLA system, with the indication of allele turnover and antigen-driven positive selection especially at the B locus, probably due to historical processes of population changes in number, and to diversified exposure to infectious agents; 5. Certainly, many genetic differences could be detected along the continent. Some of them are clinal, while others are more abrupt. In a way this would be expected, due to the varied amount of population movements and of distinct environments they had to face.

Amerindians provide a good model for evolutionary studies due to many reasons: the date of their entrance in the continent is established within reasonable limits, and many studies had been undertaken among them that involved not only genetics, but other areas that are essential for evolutionary interpretations, such as demography, epidemiology and social anthropology. Let us hope that the present trend towards essentially applied investigations will not hamper further progress in the understanding of the past, present, and eventually future of this marvellous branch of humanity. But the perspectives certainly are not bright. 


\section{ACKNOWLEDGMENTS}

Our research, duly approved by local and national ethics committees, receive financial support from the Programa de Apoio a Núcleos de Excelência (PRONEX), Conselho Nacional de Desenvolvimento Científico e Tecnológico (CNPq), and Fundação de Amparo à Pesquisa do Estado do Rio Grande do Sul (FAPERGS). The friendly cooperation of the members and leaders of the communities studied is gratefully acknowledged.

\section{RESUMO}

Foi realizada uma revisão quanto à variabilidade molecular presente em populações indígenas das Américas do Norte, Central e do Sul. Ela envolveu resultados sobre DNA antigo, DNA mitocondrial em populações atuais, HLA e outros marcadores autossômicos, variação nos cromossomos X e Y, bem como dados de virus parasitas que podem mostrar mudanças coevolucionárias. As questões consideradas foram a sua origem, maneiras como ocorreu a colonização pré-histórica do continente, tipos e níveis da variabilidade que foi desenvolvida, peculiaridades dos processos evolucionários em ameríndios, e a eventual heterogeneidade genética que surgiu em diferentes áreas geográficas. Apesar de que já foi obtida muita informação, ela é muito heterogênea quanto a populações e tipos de sistemas genéticos investigados. Infelizmente, a tendência atual a favorecer pesquisas essencialmente aplicadas sugere que esta situação não deverá melhorar no futuro.

Palavras-chave: ameríndios, polimorfismos genéticos, variabilidade genética populacional, microevolução humana.

\section{REFERENCES}

Adams EJ, Martinez-Naves E, Arnett KL, Little A-M, Tyan DB and Parham P. 1995a. HLA-B16 antigens: Sequence of the ST-16 antigen, further definition of two B38 subtypes and evidence for convergent evolution of $B * 3902$. Tiss Antigens 45: 18-26.

Adams EJ, Little A-M, Arnett KL, Leushner J AND PARHAM P. 1995b. Identification of a novel HLAB40 allele $(B * 4008)$ in a patient with leukemia. Tiss Antigens 46: 204-205.
Agostini HT, Yanagihara R, Davis V, RyschKewitsCh CF AND Stoner GL. 1997. Asian genotypes of JC virus in Native Americans and in a Pacific Island population: Markers of viral evolution and human migration. Proc Natl Acad Sci USA 94: 14542-14546.

Antúnez-De-Mayolo G, Thomas E, Reategui EP, Brown MD AND Herrera RJ. 1999. Worldwide distribution of a polymorphic Alu insertion in the progesterone receptor gene. In: PAPIHA SS, DeKa R AND Chakraborty R (eds.) Genomic diversity: Applications in human population genetics. New York, Kluwer/Plenum, pp. 213-222.

Armour JAL, Anttinen T, May CA, Vega EE, SaJANTIlA A, KidD JR, KidD KK, Bertranpetit J, PäÄвo S AND JefFreys AJ. 1996. Minisatellite diversity supports a recent African origin for modern humans. Nature Genet 13: 154-160.

Arnaiz-Villena A, Vargas-Alarcón G, Granados J, Gómez-Casado E, Longas J, Gonzales-Hevilla M, Zuñiga J, Salgado N, Hernández-Pacheco G, Guillen J and Martinez-Laso J. 2000. HLA genes in Mexican Mazatecans, the peopling of the Americas and the uniqueness of Amerindians. Tiss Antigens 56: 405-416.

Arruda VR, Grignolli CE, Gonçalves MS, Soares MC, Menezes R, SaAd STO and Costa FF. 1998. Prevalence of homozygosity for the deleted alleles of glutathione S-transferase mu (GSTM1) and theta (GSTT1) among distinct ethnic groups from Brazil: Relevance to environmental carcinogenesis? Clin Genet 54: 210-214.

Azofeifa J, Barrantes R And Cremer M. 1995. Lack of a BglII site at the 5' region of the PGK1 locus: A new variant discovered in two Chibchan Amerindian groups. Hum Genet 96: 626-627.

Bailliet G, Rothhammer F, Carnese FR, Bravi CM AND BIANCHI NO. 1994. Founder mitochondrial haplotypes in Amerindian populations. Am J Hum Genet 55: 27-33.

Barley J, Blackwood A, Carter ND, Crews DE, Cruickshank JK, JefFery S, Ogunlesi AO And Sagnella GA. 1994. Angiotensin converting enzyme insertion/deletion polymorphism: Association with ethnic origin. J Hypert 12: 955-957.

Bassères DS, Salles TSI, Costa FF And SAAd STO. 1998. Presence of allele $\alpha^{\text {lely }}$ in an Amazonian In- 
dian population. Am J Hematol 57: 212-214.

Batista O, Kolman CJ and Bermingham E. 1995. Mitochondrial DNA diversity in the Kuna Amerindians of Panamá. Hum Mol Genet 4: 921-929.

Battilana J, Bonatto SL, Freitas LB, Hutz MH, Weimer TA, Callegari-Jacques SM, Batzer MA, Hill K, Hurtado AM, Tsuneto LT, Petzl-Erler ML and Salzano FM. 2002. Alu insertions vs blood group plus protein genetic variability in four Amerindian populations. Ann Hum Biol (in press).

Batzer MA, Stoneking M, Alegria-Hartman M, Bazan H, Kass DH, Shaikh TH, Novick GE, IoANNOU PA, ScheEr WD, Herrera RJ AND DEININGER PL. 1994. African origin of human-specific polymorphic Alu insertions. Proc Natl Acad Sci USA 91: 12288-12292.

Belich MP, Madrigal JA, Hildebrand WH, Zemmour J, Williams RC, Luz R, Petzl-Erler ML and PARHAM P. 1992. Unusual HLA-B alleles in two tribes of Brazilian Indians. Nature 357: 326-333.

Bevilaqua LRM, Mattevi VS, Ewald GM, Salzano FM, Coimbra CEA JR, Santos RV and Hutz MH. 1995. Beta-globin gene cluster haplotype distribution in five Brazilian Indian tribes. Am J Phys Anthropol 98: 395-401.

Bianchi NO, Bailliet G And Bravi CM. 1995. Peopling of the Americas as inferred through the analysis of mitochondrial DNA. Braz J Genet 18: 661-668.

Bianchi NO, Bailliet G, Bravi CM, Carnese FR, Rothhammer F, Martínez-Marignac L AND PENA SDJ. 1997. Origin of Amerindian Ychromosomes as inferred by the analysis of six polymorphic markers. Am J Phys Anthropol 102: 79-89.

Bianchi NO, Catanesi Ci, Bailliet G, MartínezMarignac VL, Bravi CM, Vidal-Rioja LB, HerRERA RJ AND LóPEZ-CAMElo JS. 1998. Characterization of ancestral and derived Y-chromosome haplotypes of New World native populations. Am J Hum Genet 63: 1862-1871.

BLACK FL. 1997. Tracing prehistoric migrations by the viruses they carry: Human T-Cell Lymphotropic Viruses as markers of ethnic relationships. Hum Biol 69: 467-482.

Blagitko N, O’Huigin C, Figueroa F, Horai S, Sonoda S, Tajima K, Watkins D and Klein J. 1997. Polymorphism of the HLA-DRB1 locus in Colom- bian, Ecuadorian, and Chilean Amerinds. Hum Immunol 54: 74-81.

Bogdawa HM, Hutz MH, Salzano FM and Weimer TA. 2000. Diversity of two short tandem repeat loci (CD4 and F13A1) in three Brazilian ethnic groups. Hum Biol 72: 1045-1053.

Boissinot S, Chevret P and Furano AV. 2000. L1 (LINE-1) retrotransposon evolution and amplification in recent human history. Mol Biol Evol 17: 915928.

Bonatto SL and Salzano FM. 1997a. A single and early migration for the peopling of the Americas supported by mitochondrial DNA sequence data. Proc Nat Acad Sci USA 94: 1866-1871.

Bonatto SL and Salzano FM. 1997b. Diversity and age of the four major mtDNA haplogroups, and their implications for the peopling of the New World. Am J Hum Genet 61: 1413-1423.

Bortolini MC And SALzano FM. 1996. mtDNA diversity analysis in Amerindians and other human populations - how different are they? Braz J Genet 19: 527-534.

Bortolini MC, Salzano FM, Bau CHD, Layrisse Z, Petzl-Erler ML, Tsuneto LT, Hill K, Hurtado AM, Castro-de-Guerra D, Bedoya G and RuizLiNARES A. 2002. Y-chromosome biallelic polymorphisms and Native American population structure. Ann Hum Genet (in press).

Bowcock AM, Ruiz-Linares A, Tomfohrde J, Minch E, Kidd JR and Cavalli-Sforza LL. 1994. High resolution of human evolutionary trees with polymorphic microsatellites. Nature 368: 455-457.

Bravi CM, Bailliet G, Martínez-Marignac VL and BIANCHI NO. 2000. Origin of YAP+ lineages of the human Y-chromosome. Am J Phys Anthropol 112: 149-158.

Bravi CM, Bailliet G, Martínez-Marignac VL and BiAnCHI NO. 2001. Tracing the origin and geographic distribution of an ancestral form of the human Y chromosome. Rev Chil Hist Nat 74: 139-149.

Briceno I, Gomez A, Bernal JE and Papiha SS. 1996. HLA-DPB1 polymorphism in seven South American Indian tribes in Colombia. Eur J Immunogenet 23: 235-240.

Brown MD, Hosseini SH, Torroni A, Bandelt H-J, Allen JC, Schurr TG, Scozzari R, Cruciani F 
AND Wallace DC. 1998. mtDNA haplogroup X: An ancient link between Europe/Western Asia and North America? Am J Hum Genet 63: 1852-1861.

Buchanan AV, Risch GM, Robichaux M, Sherry ST, BAtZer MA AND Weiss KM. 2000. Long DOP-PCR of rare archival anthropological samples. Hum Biol 72: 911-925.

BurokeR N, Day J, Maclaren D, Sweeny K, Scott CR AND CHEn S-H. 1997. Population genetics of the D4S139, D10S28, D17S74 and D17S79 VNTR loci among Asian, Black, Caucasian, Hispanic and Native American populations from Seattle. Gene Geogr 11: $1-14$.

CAdavid LF And Watkins DI. 1997. Heirs of the jaguar and the anaconda: HLA, conquest and disease in the indigenous populations of the Americas. Tiss Antigens 50: 209-218.

Calafell F, Shuster A, Speed WC, Kidd JR and Kidd KK. 1998. Short tandem repeat polymorphism evolution in humans. Europ J Hum Genet 6: 38-49.

Calafell F, Shuster A, Speed WC, Kidd JR, Black FL AND KIDD KK. 1999. Genealogy reconstructing from short tandem repeat genotypes in an Amazonian population. Am J Phys Anthropol 108: 137-146.

Carbone MA, Mackay N, Ling M, Cole DEC, Douglas C, Rigat B, Feingenbaum A, Clarke JTR, Haworth JC, Greenberg CR, Seargent L and RoBINSON BH. 1998. Amerindian pyruvate carboxylase deficiency is associated with two distinct missense mutations. Am J Hum Genet 62: 1312-1319.

Carvalho-Silva DR, Santos FR, Hutz MH, Salzano FM AND Pena SDJ. 1999. Divergent human Y-chromosome microsatellite evolution rates. J Mol Evol 49: 204-214.

Castaño AR and López de Castro JA. 1991. Structure of the HLA-A*0204 antigen, found in South American Indians. Spatial clustering of HLA-A2 subtype polymorphism. Immunogenetics 34: 281-285.

Cavalli-Sforza Ll, Menozzi P and Piazza A. 1994. The history and geography of human genes. Princeton: Princeton University Press.

Cerna M, Falco M, Friedman H, Raimondi E, MacCagno A, Fernández-Viña M and Stastny P. 1993. Differences in HLA class II alleles of isolated South American Indian populations from Brazil and Argentina. Hum Immunol 37: 213-220.
Chakraborty R, Deka R, Jin L and Ferrell RE. 1992. Allele sharing at six VNTR loci and genetic distances among three ethnically defined human populations. Am J Hum Biol 4: 387-397.

Chang F-M, Kidd JR, Livak KJ, PAKstis AJ AND KidD KK. 1996. The world-wide distribution of allele frequencies at the human dopamine D4 receptor locus. Hum Genet 98: 91-101.

Chen JJ, Hollenbach JA, Trachtenberg EA, Just JJ, Carrington M, R $\phi$ nningen KS, Begovich P, King M-C, McWeeney S, Mack SJ, Erlich HA AND Thomson G. 1999. Hardy-Weinberg testing for HLA class II (DRB1, DQA1, DQB1, and DPB1) loci in 26 human ethnic groups. Tiss Antigens 54: 533542.

Chiba AK, Bordin JO, Kuwano St, Figueiredo MS, Carvalho KI, Vieira-Filho JP and Kerbauy J. 2000. Platelet alloantigen frequencies in Amazon Indians and Brazilian blood donors. Transf Med 10: 207-212.

Choo SY, Fan L-A and Hansen JA. 1993. Allelic variations clustered in the antigen binding sites of HLABw62 molecules. Immunogenetics 37: 108-113.

Covas DT, Delgado M, Zeitune MM, Guerreiro JF, SAntos SEB AND ZAGo MA. 1997. Gene frequencies of the HPA-1 and HPA-2 platelet antigen alleles among the Amerindians. Vox Sang 73: 182-184.

Crawford MH. 1998. The origins of Native Americans. Evidence from Anthropological Genetics. Cambridge: Cambridge University Press.

Crews DE, Kamboh MI, Mancilha-Carvalho JJ and KotTKe B. 1993. Population genetics of apolipoprotein A-4, 5, and $\mathrm{H}$ polymorphisms in Yanomami Indians of northewestern Brazil: Associations with lipids, lipoproteins, and carbohydrate metabolism. Hum Biol 65: 211-224.

de Andrade FM, Coimbra CEA JR, Santos RV, GoiCOEchea A, Carnese FR, SAlzano FM and Hutz MH. 2000. High heterogeneity of apolipoprotein E gene frequencies in South American Indians. Ann Hum Biol 27: 29-34.

de Andrade FM, Ewald GM, Salzano FM and Hutz MH. 2002. Lipoprotein lipase and APOE/APOC-I/ APOC-II gene cluster diversity in Native Brazilian populations. Am J Hum Biol (in press).

Dean M, Stephens C, Winkler C, Lomb DA, Rams- 
burg M, Boaze R, Stewart C, Charbonneau L, Goldman D, Albaugh BJ, Goedert JJ, Beasley RP, HWANG L-Y, BuCHBINDER S, WEEDON M, JOHNSON PA, EICHELbERGER M AND O'Brien SJ. 1994. Polymorphic admixture typing in human ethnic populations. Am J Hum Genet 55: 788-808.

Deka R and Chakraborty R. 1999. Trinucleotide repeats, genetic instability and variation in the human genome. In: PaPiha SS, Deka R AND ChaKraBORTY R (eds.) Genomic diversity: Applications in human population genetics. New York, Kluwer/ Plenum, pp. 53-64.

Deka R, Chakraborty R and Ferrell RE. 1991. A population genetic study of six VNTR loci in three ethnically defined populations. Genomics 11: 83-92.

Deka R, Decroo S, Jin L, McGarvey ST, Rothhammer F, Ferrell RE and Chakraborty R. 1994. Population genetic characteristics of the D1S80 locus in seven human populations. Hum Genet 94: 252-258.

Deka R, Jin L, Shriver MD, Yu LM, Saha N, BarRantes R, Chakraborty R and Ferrell RE. 1996. Dispersion of human $\mathrm{Y}$ chromosome haplotypes based on five microsatellites in global populations. Genome Res 6: 1177-1184.

Deka R, Shriver MD, Yu LM, Heidrich EM, Jin L, Zhong Y, McGarvey ST, Agarwal SS, Bunker CH, Miki T, Hundrieser J, Yin S-J, Raskin S, Barrantes R, Ferrell RE AND Chrakraborty R. 1999. Genetic variation at twenty three microsatellite loci in sixteen human populations. J Genet 78: 99-121.

Demarchi DA, Marcellino AJ, de Basualdo MAL, Colantonio SE, de Stefano GF, Hutz MH, Salzano FM, Hill K, Hurtado AM, Carnese FR, Goicoechea AS, Dejean CB, Guevara AG and Crawford MH. 1999. Apolipoprotein B signal peptide polymorphism distribution among South Amerindian populations. Hum Biol 71: 995-1000.

Destro-Bistrol G, Capelli C and Belledi M. 2000. Inferring microevolutionary patterns from allele-size frequency distribution of minisatellite loci: A worldwide study of the APOB 3' hypervariable region polymorphism. Hum Biol 72: 733-751.

di Rienzo A, Donnelly P, Toomajian C, Sisk B, Hill A, Petzl-Erler ML, Haines GK and Barch DH. 1998. Heterogeneity of microsatellite mutations within and between loci and implications for human demographic histories. Genetics 148: 1269-1284.

Domena JD, Little A-M, Arnett KL, Adams EJ, Marsh SGE ANd Parham P. 1994. A small test of a sequence-based typing method: Definition of the $B * 1520$ allele. Tiss Antigens 44: 217-224.

Doran GH, Dickel DN, Agee FO, Ballinger WA, LAIPIS PJ AND HAusWIRTH WW. 1986. 8000 year old human brain tissue: Anatomical, cellular and molecular analysis. Nature 323: 803-806.

Dornelles CL, Bonatto SL, Freitas LB, Fagundes NJR, Muschner V and Salzano FM. 2000. Análise do DNA mitocondrial em populações indígenas sul-americanas: A presença do haplogrupo X. Genet Molec Biol 23(3, suppl): 582.

Duncan G, Thomas E, Gallo JC, Baird LS, Garrison J AND Herrera RJ. 1996. Human phylogenetic relationships according to the D1S80 locus. Genetica 98: 277-287.

Easton RD, Merriwether DA, Crews DE and FerRELL RE. 1996. mtDNA variation in the Yanomami: Evidence for additional New World founding lineages. Am J Hum Genet 59: 213-225.

Erlich HA, Mack SJ, Bergström T and GyllenSTEN UB. 1997. HLA class II alleles in Amerindian populations: Implications for the evolution of HLA polymorphism and the colonization of the Americas. Hereditas 127: 19-24.

FAgundes NJR, Batzer MA, Deininger PL, Salzano FM, Freitas LB and Bonatto SL. 2002. The 3'UTR of the LDLR gene - a highly variable human nuclear locus (submitted).

FernándeZ-Viña MA, LÁZaro AM, Marcos CY, NulF C, Raimondi E, Haas EJ and Stastny P. 1997. Dissimilar evolution of B-locus versus A-locus and class II loci of the HLA region in South American Indian tribes. Tiss Antigens 50: 233-250.

Forster P, Röhl A, LÜNnEMANn P, Brinkmann C, Zerjal T, Tyler-Smith C And Brinkmann B. 2000. A short tandem repeat-based phylogeny for the human Y chromosome. Am J Hum Genet 66: 182-196.

Franco RF, Simões BP, Guerreiro JF, Santos SEB AND ZAGo MA. 1994. Molecular bases of the ABO blood groups of Indians from the Brazilian Amazon region. Vox Sang 67: 299-301.

Franco RF, Guerreiro JF, Zago MA ANd Figueiredo 
MS. 1996. Factor VIII gene polymorphisms in Amerindians from the Brazilian Amazon region. Braz J Genet 19: 351-354.

Franco RF, Araújo AG, Zago MA, Guerreiro JF AND FigueIREDO MS. 1997. Factor IX gene haplotypes in Amerindians. Hum Biol 69: 1-9.

Frégeaux CJ, TAN-Siew WF, YAP KH, CARMody GR, Chow ST And Fourney RM. 1998. Population genetic characteristics of the STR loci D21S11 and FGA in eight diverse human populations. Hum Biol 70: 813-844.

Fullerton SM, Clark AG, Weiss KM, Nickerson DA, Taylor SL, Stengärd JH, Salomaa V, Vartiainen E, Perola M, Boerwinkle E and Sing CF. 2000. Apolipoprotein E variation at the sequence haplotype level: Implications for the origin and maintenance of a major human polymorphism. Am J Hum Genet 67: 881-900.

Gaedigk A, Tyndale RE, Jurima-Romet M, Sellers EM, GRANT DM AND LEEDER JS. 1998. NAD(P)H: quinone oxidoreductase: Polymorphisms and allele frequencies in Caucasian, Chinese and Canadian Native Indian and Inuit populations. Pharmacogenetics 8: 305-313.

Gamboa R, Hernandez-Pacheco G, Hesiquio R, Zuñiga J, Massó F, Montaño LF, RamosKuri M, Estrada J, Granados J and VargasAlarcón G. 2000. Apolipoprotein E polymorphism in the Indian and Mestizo populations of México. Hum Biol 72: 975-981.

Garber TL, Butler LM, Trachtenberg EA, Erlich HA, Rickards O, De Stefano G and Watkins DI. 1995. HLA-B alleles of the Cayapa of Ecuador: New $B 39$ and B15 alleles. Immunogenetics 42: 19-27.

Gaspar PA, Hutz MH, Salzano FM and Weimer TA. 2001. TP53 polymorphisms and haplotypes in South Amerindians and neo-Brazilians. Ann Hum Biol 28: 184-194.

Gené M, Fuentes M, Hughet E, Piqué E, Bert F, Corella A, Pérez-Pérez A, Corbella J AND Moreno P. 1998. Quechua Amerindian population characterized by HLA-DQ $\alpha$, INZ22, 3'APO B, HUMTH01, and HUMVWA31A polymorphisms. J For Sci 43: 403-405.

Ginther C, Corach D, Penacino GA, Rey JA, Carnese FR, Hutz MH, Anderson A, Just J, SAlzano
FM AND KING M-C. 1993. Genetic variation among the Mapuche Indians from the Patagonian region of Argentina: Mitochondrial DNA sequence variation and allele frequencies of several nuclear genes. In: Pena SDJ, Chakraborty R, Epplen JT and JefFREYS AJ (eds.) DNA fingerprinting: State of the science. Basel: Birkhäuser Verlag, pp. 211-219.

Goldman D, Urbanek M, Guenther D, Robin R AND LONG JC. 1997. Linkage and association of a functional DRD2 variant [Ser311Cys] and DRD2 markers to alcoholism, substance abuse and schizophrenia in Southwestern American Indians. Am J Med Genet 74: 386-394.

Gomez-Casado E, Montoya F, Martinez-Laso J, Bedoya CI, Varela P, Diaz-Campos N and Arnaiz-Villena A. 1995. A new HLA-B35 allele $(B * 3510)$ found in isolated Jaidukama South American Indians. Immunogenetics 42: 231-232.

Gómez-Casado E, Martínez-Laso J, GonzalezHevilla M, Longas J, Rubio I, SilveraRedondo C, Garcia-Gomez A, Lowy E AND Arnaiz-Villena A. 2000. A novel HLA-A*6816 allele possibly generated by a point mutation in a Chilean from Punta Arenas (Magellan Strait). Immunogenetics 51: 257-260.

Gu X AND Nei M. 1999. Locus specificity of polymorphic alleles and evolution by a birth-and-death process in mammalian MHC genes. Mol Biol Evol 16: 147156.

Guarino FD, Federle L, Van Dorschot RAH, Briceno I, Bernal JE, Papiha SS, Schanfield MS AND Mitchell RJ. 1999. Genetic diversity among five Native American tribes of Colombia. Evidence from nine autosomal microsatellites. In: PAPIHA SS, Deka R and Chakraborty R (eds.) Genomic diversity. Applications in human population genetics. New York, Kluwer/Plenum, pp. 33-51.

Guédez YB, Layrisse Z, Dominguez E, RodrigueZLARRAldE A AND ScorZa J. 1994. Molecular analysis of MHC class II alleles and haplotypes (DRB1, DQA1 and DQB1) in the Bari Amerindians. Tiss Antigens 44: 125-128.

Guerreiro JF, Figueiredo MS, SANTos SEB ANd ZaGo MA. 1992. $\beta$-globin gene cluster haplotypes in Yanomama Indians from the Amazon region of Brazil. Hum Genet 89: 629-631. 
Guerreiro JF, Figueiredo MS and Zago, MA. 1994. Beta-globin gene cluster haplotypes of Amerindian populations from the Brazilian Amazon region. Hum Hered 44: 142-149.

Hammer MF and Zegura SL. 1996. The role of the Y chromosome in human evolutionary studies. Evol Anthropol 5: 116-134.

Hammer MF, Spurdle AB, Karafet T, Bonner MR, Wood ET, Novelletto A, Malaspina P, Mitchell RJ, Horai S, Jenkins T and Zegura SL. 1997. The geographic distribution of human Y chromosome variation. Genetics 145: 787-805.

Hammer MF, Karafet T, Rasanayagam A, Wood ET, Altheide TK, Jenkins T, Griffiths RC, TempleTON AR AND ZEGURA SL. 1998. Out of Africa and back again: Nested cladistic analysis of human Y chromosome variation. Mol Biol Evol 15: 427-441.

Handt O, Krings M, Ward RH AND PäÄвo S. 1996. The retrieval of ancient human DNA sequences. Am J Hum Genet 59: 368-376.

HARding RM, Fullerton SM, GrifFiths RC, Bond J, Cox MJ, Schneider JA, Moulin DS ANd ClegG JB. 1997. Archaic African and Asian lineages in the genetic ancestry of modern humans. Am J Hum Genet 60: $772-789$.

HaRdy GH. 1908. Mendelian proportions in a mixed population. Science 28: 49-50.

Hauswirth WW, Dickel CD, Doran GH, Laipis PJ AND DiCKEL DN. 1991. 8000-year-old brown tissue from the Windower site: Anatomical, cellular, and molecular analysis. In: ORTNER DJ AND AufDERHEIDE AC (eds.) Human paleopathology. Current synthesis and future options. Washington: Smithsonian Institute Press, pp. 60-72.

Hauswirth WW, Dickel CD, Rowold DJ and HausWIRTH MA. 1994. Inter- and intrapopulation studies of ancient humans. Experientia 50: 585-591.

Heidrich EM, Hutz MH, Salzano FM, Coimbra CEA JR AND SANTOS RV. 1995. D1S80 locus variability in three Brazilian ethnic groups. Hum Biol 67: 311319.

Herrmann B and Hummel S. 1994. Ancient DNA. Berlin: Springer-Verlag.

Herrmann FH, Salazar-Sanchez L, Schröder W, Grimm R, Schuster G, Jimenez-Arce G, Chavez M AND Singh JR. 2001. Prevalence of molecu- lar risk factors FV Leiden, FVHR2, FII20210G>A and MTHFRC $>\mathrm{T}$ in different populations and ethnic groups of Germany, Costa Rica and India. Intern J Hum Genet 1: 33-39.

Higuchi R, Bowman B, Freiberger M, Ryder OA ANd WiLson AC. 1984. DNA sequences from a quagga, an extinct member of the horse family. Nature 312 : 282-284.

Hildebrand WH, Madrigal JA, Belich MP, Zemmour J, Ward FE, Williams RC and Parham P. 1992. Serologic cross-reactivities poorly reflect allelic relationships in the HLA-B12 and HLA-B21 groups. J Immunol 149: 3563-3568.

Hildebrand WH, Domena JD, Shen SY, Lau M, Terasaki PI, Bunce M, Marsh SGE, Guttridge MG, Bias WB and Parham P. 1994. HLA-B15: A widespread and diverse family of HLA-B alleles. Tiss Antigens 43: 209-218.

Horai S, Kondo R, Nakagawa-Hattori Y, Hayashi S, Sonoda S and Tajima K. 1993. Peopling of the Americas, founded by four major lineages of mitochondrial DNA. Mol Biol Evol 10: 23-47.

Huoponen K, Torroni A, Wickman PR, Sellitto D, Gurley DS, Scozzari R and Wallace DC. 1997. Mitochondrial DNA and Y chromosome-specific polymorphisms in the Seminole of Florida. Eur $\mathbf{J}$ Hum Genet 5: 25-34.

Hutz MH, Mattevi VS, Callegari-Jacques SM, SALzano FM, Coimbra CEA Jr, Santos RV, Carnese FR, Goicoechea AS and Dejean CB. 1997. D1S80 locus variability in South American Indians. Ann Hum Biol 24: 249-255.

Hutz MH, Callegari-Jacques SM, Bortolini MC AND SAlzano FM. 1999. Variability in nDNA, mtDNA, and proteins: A test case. In: PAPIHA SS, Deka R and Chakraborty R (eds.) Genomic diversity: Applications in human population genetics. New York, Kluwer/Plenum, pp. 23-32.

Hutz MH, Almeida S, Coimbra CEA Jr, Santos RV And Salzano FM. 2000. Haplotype and allele frequencies for three genes of the dopaminergic system in South American Indians. Am J Hum Biol 12: 638645.

Imanishi T, Akaza T, Kimura A, ToKunaga K AND GoJOBORI T. 1992. Allele and haplotype frequencies for HLA and complement loci in various ethnic groups. 
In: Tsuji K, Aizawa M and Sasazuki T (eds.) $H L A$ 1991, Vol. 1. Oxford: Oxford University Press, pp. 1065-1220.

Iwanaga KK, Eberle M, Kolman CJ, Bermingham E AND WATKINS DI. 1997. Further diversification of the HLA-B locus in Central American Amerindians: New $B * 39$ and $B * 51$ alleles in the Kuna of Panama. Tiss Antigens 50: 251-257.

Jin L, Baskett ML, CAVAlli-Sforza LL, Zhivotovsky LA, Feldman MW and Rosenberg NA. 2000. Microsatellite evolution in modern humans: A comparison of two data sets from the same populations. Ann Hum Genet 64: 117-134.

Jobling MA And Tyler-Smith C. 1995. Fathers and sons: the $\mathrm{Y}$ chromosome and human evolution. $\mathrm{Tr}$ Genet 11: 449-456.

Johnson MJ, Wallace DC, Ferris SD, Rattazzi MC AND Cavalli-Sforza LL. 1983. Radiation of human mitochondrial DNA types analyzed by restriction endonuclease cleavage patterns. J Mol Evol 19: 255-271.

Jorge LE, Eichelbaum M, Griese E-U, InAba T AND ARIAS TD. 1999. Comparative evolutionary pharmacogenetics of CYP2D6 in Ngawbe and Embera Amerindians of Panama and Colombia: Role of selection versus drift in world populations. Pharmacogenetics 9: 217-228.

Juul L, Hougs L, Andersen V, Garred P, Ryder L, Svejgaard A, Høgh B, Lamm L, Graugaard B AND Barington T. 1997. Population studies of the human Vk A18 gene polymorphism in Caucasians, blacks and Eskimos. Tissue Antigens 49: 595-604.

Karafet T, Segura SL, Vuturo-Brady J, Posukh O, Osipova L, Wiebe V, Romero F, Long JC, Harihara S, Jin F, Dashnyam B, Gerelsaikhan T, Омото K ANd Hammer MF. 1997. Y chromosome markers and trans-Bering Strait dispersals. Am J Phys Anthropol 102: 301-314.

Karafet T, de KnijfF P, Wood E, Ragland J, Clark A AND HAMmer MF. 1998. Different patterns of variation at the X- and Y-chromosome-linked microsatellite loci DXYS156X and DXYS156Y in human populations. Hum Biol 70: 979-992.

Karafet TM, Zegura SL, Posukh O, Osipova L, Bergen A, Long J, Goldman D, Klitz W, Harihara S, De KniJfF P, Wiebe V, Griffiths RC, Tem-
PLETON AR AND HAMmer MF. 1999. Ancestral Asian source(s) of New World Y-chromosome founder haplotypes. Am J Hum Genet 64: 817-831.

Kaufman L, Carnese FR, Goicoechea AS, Dejean C, Salzano FM and Hutz MH. 1998. Beta-globin gene cluster haplotypes in the Mapuche Indians of Argentina. Genet Mol Biol 21: 435-437.

Kaufman L, Vargas AF, Coimbra CEA Jr, Santos RV, Salzano FM ANd Hutz MH. 1999. Apolipoprotein $\mathrm{B}$ genetic variability in Brazilian Indians. Hum Biol 71: 87-98.

Kayser M, Krawczak M, Excoffier L, Dieltjes P, Corach D, Pascali V, Gehrig C, Bernini LF, JesPERSEN J, BAKKer E, Roewer L AND DE KNIJfF P. 2001. An extensive analysis of Y-chromosomal microsatellite haplotypes in globally dispersed human populations. Am J Hum Genet 68: 990-1018.

Kessler D, Moehlenkamp C and Kaplan G. 1996. Determination of cystic fibrosis carrier frequency for Zuni Native Americans of New Mexico. Clin Genet 49: 95-97.

Keyeux G, Rodas MC and Jaramillo-Correa JP. 2001. The Yuko from Colombia: An example of bottleneck effect in an Amerindian population. Am J Hum Biol 13: 127.

Kidd JR, Black FL, Weiss KM, Balazs I and KidD KK. 1991. Studies of three Amerindian populations using nuclear DNA polymorphisms. Hum Biol 63: 775-794.

Kidd JR, Pakstis AJ, Zhao H, Lu R-B, OKonofua FE, Odunsi A, Gricorenko E, Bonne-TAMir B, FriedLAENDER J, Schulz LO, PARnas J AND KidD KK. 2000. Haplotypes and linkage disequilibrium at the phenylalanine hydroxylase locus, $P A H$, in a global representation of populations. Am J Hum Genet 66: 1882-1899.

Kidd KK, Morar B, Castiglione CM, Zhao H, Pakstis AJ, Speed WC, Bonne-Tamir B, Lu R-B, GoldMAN D, LeE C, NAM YS, GRandy DK, Jenkins T AND KIDD JR. 1998. A global survey of haplotype frequencies and linkage disequilibrium at the DRD2 locus. Hum Genet 103: 211-227.

Kittles RA, Bergen AW, Urbanek M, Virkkunen M, Linnoila M, Goldman D and Long JC. 1999. Autosomal, mitochondrial, and Y chromosome DNA variation in Finland: Evidence for a male-specific 
bottleneck. Am J Phys Anthropol 108: 381-399.

Knight A, Batzer MA, Stoneking M, Tiwari HK, Douglas Scheer W, Herrera RJ and Deininger PL. 1996. DNA sequences of Alu elements indicate a recent replacement of the human autosomal genetic complement. Proc Natl Acad Sci USA 93: 43604364.

Kolman CJ and Bermingham E. 1997. Mitochondrial and nuclear DNA diversity in the Chocó and Chibcha Amerinds of Panama. Genetics 147: 1289-1302.

Kolman CJ And Tuross N. 2000. Ancient DNA analysis of human populations. Am J Phys Anthropol 111: 523.

Kolman CJ, Bermingham E, Cooke R, Ward RH, Arias TD and Guionneau-Sinclair F. 1995. Reduced mtDNA diversity in the Ngöbé Amerinds of Panamá. Genetics 140: 275-283.

Kunst CB, Zerylnick C, Karickhoff L, Eichler E, Bullard J, Chalifoux M, Holden JJA, Torroni A, Nelson DL and Warren ST. 1996. FMR1 in global populations. Am J Hum Genet 58: 513-522.

Kuwano ST, Bordin JO, Chiba AK, Mello AB, Figueiredo MS, Vieira-Filho JPB, FABron A JR AND Kerbauy J. 2000. Allelic polymorphisms of human Fcg receptor IIa and $\mathrm{Fc} \gamma$ receptor IIIb among distinct groups in Brazil. Transfusion 40: 13881392.

Kvitko K, Nunes JCB, Weimer TA, Salzano FM And Hutz MH. 2000. Cytochrome P4501A1 polymorphism in South American Indians. Hum Biol 72: 1039-1043.

Lalueza C, Pérez-Pérez A, Prats E, Moreno P, Pons J And Turbón D. 1993-94. Ausencia de la deleccion de 9 bp COII/tRNA ${ }^{\text {Lys }}$ en aborigenes de FuegoPatagonia mediante analisis de DNA antiguo. Ans Inst Pat 22: 181-191.

Lalueza C, Pérez-Pérez A, Prats E, Cornudella L AND TuRBón D. 1997. Lack of founding Amerindian mitochondrial DNA lineages in extinct aborigines from Tierra del Fuego-Patagonia. Hum Mol Genet 6: 41-46.

LALueza Fox C. 1996. Mitochondrial DNA haplogroups in four tribes from Tierra del Fuego-Patagonia: Inferences about the peopling of the Americas. Hum Biol 68: 855-871.

Lalueza-Fox C, Luna Calderón F, Calafell F, Mor-
ERA B AND BertranPetit J. 2001. MtDNA from extinct Tainos and the peopling of the Caribbean. Ann Hum Genet 65: 137-151.

Layrisse Z, Guedez Y, Dominguez E, Herrera F, Soto M, Balbas O, Matos M, Alfonzo JC, Granados J AND Scorza J. 1995. Extended HLA haplotypes among the Bari Amerindians of the Perija range. Relationship to other tribes based on four-loci haplotype frequencies. Hum Immunol 45: 228-235.

Lazaro AM, Marcos CY, Fernández-Vĩ̃a MA, Moraes ME, Moraes JR and Stastny P. 1998. Brazilian Terena normal. In: GJERTSON DW AND Terasaki PI (eds.) HLA 1998. Lenexa: American Society of Histocompatibility and Immunogenetics, pp 224-225.

Leboute AP, de Carvalho MW and Simoes AL. 1999. Absence of the deltaccr5 mutation in indigenous populations of the Brazilian Amazon. Hum Genet 105: 442-443.

LELl JT, Brown MD, Schurr TG, SUKERNIK RI, StARIkovskaya YB, Torroni A, Moore LG, Troup GM AND Wallace DC. 1997. Y chromosome polymorphisms in Native American and Siberian populations: Identification of Native American Y chromosome haplotypes. Hum Genet 100: 536-543.

Lleonart R, Riego E, SuÁrez RR, Ruiz RT AND DE LA Fuente J. 1999. Analyses of DNA from ancient bones of a pre-Columbian Cuban woman and a child. Genet Molec Biol 22: 285-289.

Lorenz JG AND SMITH DG. 1996. Distribution of four founding mtDNA haplogroups among Native North Americans. Am J Phys Anthropol 101: 307-323.

Luiselli D, Maiolini E, Pelotti S, Bini C, Ferri G and Pappalardo G. 2001. The HUMFIBRA (FGA) polymorphism in an Italian population and a worldwide frequency distribution analysis. Ann Hum Biol 28: 431-443.

MACK SJ AND ERLICH HA. 1998. HLA class II polymorphism in the Ticuna of Brazil: Evolutionary implications of the $D R B 1 * 0807$ allele. Tiss Antigens 51: 41-50.

Marcos CY, FERnÁNdEZ-ViÑa MA, LÁZARo AM, NulF CJ, Raimondi EH and Stastny P. 1997. Novel HLA-B35 subtypes. Putative gene conversion events with donor sequences from alleles common in $\mathrm{Na}-$

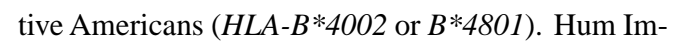


munol 53: 148-155.

Marcos CY, Fernández-Viña MA, LÁzaro AM, Moraes ME, Moraes JR and Stastny P. 1999. Novel HLA-A and HLA-B alleles in South American Indians. Tiss Antigens 53: 476-485.

Marin GB, Tavella MH, Guerreiro JF, Santos SEB AND ZAGO MA. 1997. Absence of the E2 allele of apolipoprotein in Amerindians. Braz J Genet 20: 741-743.

Martinez-Laso J, Layrisse Z, Gomez-Casado E, Montoya F, Guédez Y, Dominguez E, Varela P AND Arnaiz-Villena A. 1995. A new HLA-B15 allele $\left(\mathrm{B}^{*} 1522\right)$ found in Bari-Motilones Amerindians in Venezuela: Comparison of its intron 2 sequence with those of $\mathrm{B} * 1501$ and $\mathrm{B} * 3504$. Immunogenetics 43: 108-109.

Mateu E, Calafell F, Bonné-Tamir B, Kidd JR, Casals T, Kidd KK and Bertranpetit J. 1999. Allele frequencies in a worldwide survey of a CA repeat in the first intron of the CFTR gene. Hum Hered 49: 15-20.

Mateu E, Calafell F, Lao O, Bonné-Tamir B, Kidd JR, PAKstis A, Kidd KK ANd Bertranpetit J. 2001. Worldwide genetic analysis of the CFTR region. Am J Hum Genet 68: 103-117.

Mathias N, Bayes M and Tyler-Smith C. 1994. Highly informative compound haplotypes for the human Y chromosome. Hum Mol Genet 3: 115-123.

Mattevi VS, Coimbra CEA Jr, Santos RV, Salzano FM AND Hutz MH. 2000a. Association of the lowdensity receptor gene with obesity in Native American populations. Hum Genet 106: 546-552.

Mattevi VS, Fiegenbaum M, Salzano FM, Weiss KM, Moore J, Monsalve MV, Devine DV and Hutz MH. 2000b. Beta-globin gene cluster haplotypes in two North American indigenous populations. Am J Phys Anthropol 112: 311-317.

McComb J, CrawFord MH, LEONARd WR, SchanFIELd MS AND Osipova L. 1996. Applications of DNA fingerprints for the study of genetic structure of human populations. In: Gustafson JP AND FLAVELl RB (eds.) Genomes of plants and animals: $21^{\text {st }}$ Stadler Genetics Symposium. New York: Plenum, pp. 3146.

Mercier B, Raguénès O, Estivill X, Morral N, KaPlan GC, McClure M, Grebe TA, Kessler D, Pig- natti PF, Marigo C, Bombieri C, Audrézet MP, Verlingue C And Férec C. 1994. Complete detection of mutations in cystic fibrosis patients of Native American origin. Hum Genet 94: 629-632.

Merriwether DA, Rothhammer F and Ferrell RE. 1994. Genetic variation in the New World: Ancient teeth, bone, and tissue as sources of DNA. Experientia 50: 592-601.

Merriwether DA, Rothhammer F and Ferrell RE. 1995. Distribution of the four founding lineage haplotypes in Native Americans suggests a single wave of migration for the New World. Am J Phys Anthropol 98: 411-430.

Merriwether DA, Hall WW, Vahlne A and Ferrell RE. 1996. mtDNA variation indicates Mongolia may have been the source for the founding population for the New World. Am J Hum Genet 59: 204-212.

Merriwether DA, Kemp BM, Crews DE and Neel JV. 2000. Gene flow and genetic variation in the Yanomama as revealed by mitochondrial DNA. In: RENFrew C (ed.) America past, America present: Genes and languages in the Americas and beyond. Cambridge: McDonald Institute for Archaeological Research, pp. 89-124.

Mesa NR, Mondragón MC, Soto ID, Parra MV, Duque C, Ortiz-Barrientos D, García LF, Velez ID, Bravo ML, Múnera JG, Bedoya G, BorTOLini MC AND Ruiz-Linares A. 2000. Autosomal, mtDNA, and Y-chromosome diversity in Amerinds: Pre and post-Columbian patterns of gene flow in South America. Am J Hum Genet 67: 12771286.

Meyer D And Thomson G. 2001. How selection shapes variation of the human major histocompatibility complex: A review. Ann Hum Genet 65: 1-26.

MHC Sequencing Consortium. 1999. Complete sequence and gene map of a human major histocompatibility complex. Nature 401: 921-923.

Mingroni-Netto RC, Angeli CB, Auricchio MTBM, Mesquita ERL, Ribeiro-dos-Santos AKC, Ferrari I, Hutz MH, Salzano FM, Hill K, Hurtado AM and Vianna-Morgante AM. 2002. Distribution of CGG repeats and FRAXAC1/DXS548 alleles in South American populations (submitted).

Mitchell RJ. 1996. Y-chromosome-specific restriction fragment length polymorphisms (RFLPs): Rel- 
evance to human evolution and human variation. Am J Hum Biol 8: 573-586.

Mitchell RJ, Howlett S, White NG, Federle L, Papiha SS, Briceno I, McComb J, SchanField MS, Tyler-Smith C, Osipova L, Livshits G AND CRAwFord MH. 1999. Deletion polymorphism in the COL1A2 gene: Genetic evidence of a non-African population whose descendants spread to all continents. Hum Biol 71: 901-914.

Mitchell RJ, Federle L, Sofro ASM, Papiha SS, Briceno I AND BERnAL JE. 2000a. Further data on the microsatellite locus D12S67 in worldwide populations: An unusual distribution of D12S67 alleles in Native Americans. Hum Biol 72: 697-705.

Mitchell RJ, Howlett S, Earl L, White NG, McComb J, Schanfield MS, Briceno I, Papiha SS, Osipova L, Livshits G, LeONARd WR AND CRAWFORD MH. 2000b. Distribution of the 3' VNTR polymorphism in the human dopamine transporter gene in world populations. Hum Biol 72: 295-304.

Miura T, Yamashita M, Zaninovic V, Cartier L, Takehisa J, Igarashi T, Ido E, Fujiyoshi T, Sonoda S, Tajima K and Hayami M. 1997. Molecular phylogeny of human T-Cell Leukemia Virus Type I and II of Amerindians in Colombia and Chile. J Mol Evol 44(Suppl. 1): S76-S82.

Monsalve MV, Cardenas F, Guhl F, Delaney AD AND Devine DV. 1996. Phylogenetic analysis of mtDNA lineages in South American mummies. Ann Hum Genet 60: 293-303.

Monsalve MV, Edin G and Devine DV. 1998. Analysis of HLA class I and class II in Na-Dene and Amerindian populations from British Columbia, Canada. Hum Immunol 59: 48-55.

Monsalve MV, Helgason A and Devine DV. 1999. Languages, geography and HLA haplotypes in Native American and Asian populations. Proc R Soc Lond 266: 2209-2216.

Mourant AE. 1954. The distribution of the human blood groups. Springfield: Charles $\mathrm{C}$ Thomas.

Mourant AE, Kopeć AC and DomaniewsKa-SobczaK K. 1958. The ABO blood groups. Comprehensive tables and maps of world distribution. Oxford: Blackwell.

Mourant AE, Kopeć AC and Domaniewska-SobczaK K. 1976. The distribution of the human blood groups and other polymorphisms. London: Oxford University Press.

Muñoz S, Vollrath V, Vallejos MP, Miquel JF, Covarrubias C, Raddatz A ANd Chianale J. 1998. Genetic polymorphisms of CYP2D6, CYP1A1 and CYP2E1 in the South-Amerindian population of Chile. Pharmacogenetics 8: 343-351.

NeEL JV. 2000. Unpublished observations (personal communication).

Neel JV, Biggar RJ and Sukernik RI. 1994. Virologic and genetic studies relate Amerind origins to the indigenous people of the Mongolia/Manchuria/southeastern Siberia region. Proc Natl Acad Sci USA 91: 10737-10741.

Nei M and Takezaki N. 1996. The root of the phylogenetic tree of human populations. Mol Biol Evol 13: 170-177.

Novick GE, Novick CC, Yunis J, Yunis E, AntúneZDE-Mayolo P, Scheer WD, Deininger PL, StoneKING M, York DS, BATzer MA AND Herrera RJ. 1998. Polymorphic Alu insertions and the Asian origin of Native American populations. Hum Biol 70: 23-39.

Онта T. 1998. On the pattern of polymorphisms at major histocompatibility complex loci. J Mol Evol 46: 633638.

Онта T. 2000. An attempt to measure the patchwork pattern observed among alleles at major histocompatibility complex loci. J Mol Evol 51: 21-25.

Oliveira SF. 1999. Inserções Alu em populações indígenas da Amazônia brasileira. Ph.D. Dissertation, University of São Paulo, Ribeirão Preto.

Olivo A, Debaz H, de la Rosa G, Aláez C, Moreno M, Juárez V, Gorodezky C, Guedez Y, Domínguez E, Herrera F, Soto M, Matos M, Scorza J AND LAYRISSE Z. 1996. Alelos y haplotipos del complejo principal de histocompatibilidad en tres poblaciones indígenas americanas. Estudios serológicos y moleculares realizados en México y Venezuela. In: Martín Municio A and García Barreno P (eds.) Polimorfismo génico (HLA) en poblaciones hispanoamericanas. Madrid: Real Academia de Ciencias, pp. 195-213.

Olivo-Díaz A, Gomez-Casado E, Gorodezky C, Martinez-Laso J, Longás J, GonZÁlez-Hevilla M, Alvarez M and Arnaiz-Villena A. 1998. A new 
HLA-B15 allele $\left(B^{*} 1541\right)$ found in a Mexican of Nahua (Aztec) descent. Immunogenetics 48: 148151.

Olsson ML, Santos SEB, Guerreiro JF, Zago MA AND Chester MA. 1998. Heterogeneity of the O alleles at the blood group ABO locus in Amerindians. Vox Sang 74: 46-50.

O'Rourke DH, Carlyle SW and Parr RL. 1996. Ancient DNA: Methods, progress, and perspectives. Am J Hum Biol 8: 557-571.

O'Rourke DH, Hayes MG and Carlyle SW. 2000. Spatial and temporal stability of mtDNA haplogroup frequencies in Native North America. Hum Biol 72: 15-34.

Osier M, Pakstis AJ, Kidd JR, LeE J-F, Yin S-J, Ko H-C, Edenberg HJ, Lu R-B AND KIdD KK. 1999. Linkage disequilibrium at the ADH2 and ADH3 loci and risk of alcoholism. Am J Hum Genet 64: 11471157.

РёӒво S. 1985. Molecular cloning of ancient Egyptian mummy DNA. Nature 314: 644-645.

Рё̈̈во S. 1989. Ancient DNA: Extraction, characterization, molecular cloning, and enzymatic amplification. Proc Natl Acad Sci USA 86: 1939-1943.

PÄÄвo S, Gifford JA AND Wilson AC. 1988. Mitochondrial DNA sequences from a 7000-year old brain. Nucleic Acids Res 16: 9775-9787.

PäÄво S, Higuchi RG and Wilson AC. 1989. Ancient DNA and the polymerase chain reaction. J Biol Chem 264: 9709-9712.

Parham P and Ohta T. 1996. Population biology of antigen presentation by MHC class I molecules. Science 272: 67-74.

Parham P, Arnett KL, Adams EJ, Little A-M, Tees K, Barber LD, Marsh SGE, Ohta T, Markow T ANd Petzl-Erler ML. 1997. Episodic evolution and turnover of HLA-B in the indigenous human populations of the Americas. Tiss Antigens 50: 219-232.

Parr RL, Carlyle SW and O'Rourke DH. 1996. Ancient DNA of Fremont Amerindians of the Great Salt Lake Wetlands. Am J Phys Anthropol 99: 507-518.

Pena SDJ, Santos FR, Bianchi NO, Bravi CM, Carnese FR, Rothhammer F, Gerelsaikhan T, Munkhtuja B and Oyunsuren T. 1995. A major founder Y-chromosome haplotype in Amerindi- ans. Nature Genet 11: 15-16.

Pepe G, Rickards O, Bué C, Martinez-Labarga C, Tartaglia M and de Stefano GF. 1994. EcoRI, RsaI, and MspI RFLPs of the COL1A2 gene (Type I collagen) in the Cayapa, a Native American population of Ecuador. Hum Biol 66: 979-989.

Pepe G, Vanegas OC, Giusti B, Brunelli T, Marcucci R, Attanasio M, Rickards O, de Stefano GF, Prisco D, Gensini GF and Abbate R. 1998. Heterogeneity in world distribution of the thermolabile C677T mutation in 5, 10-methylenetetrahydrofolate reductase. Am J Hum Genet 63: 917-920.

Pérez-Lezaun A, Calafell F, Mateu E, Comas D, Bosch E and Bertranpetit J. 1997a. Allele frequencies for 20 microsatellites in a worldwide population survey. Hum Hered 47: 189-196.

Pérez-Lezaun A, Calafell F, Mateu E, Comas D, Ruiz-Pacheco R and Bertranpetit J. 1997b. Microsatellite variation and the differentiation of modern humans. Hum Genet 99: 1-7.

Peterson RJ, Goldman D and Long JC. 1999. Nucleotide sequence diversity in non-coding regions of ALDH2 as revealed by restriction enzyme and SSCP analysis. Hum Genet 104: 177-187.

Petzl-Erler ML. 1998. Kaingang Amerindian Brazil normal, Guarani Amerindian normal. In: GJERTSON DW AND Terasaki PI (eds.) HLA 1998. Lenexa: American Society of Histocompatibility and Immunogenetics, pp. 222-223.

Petzl-Erler ML, Gorodezky C, Layrisse Z, Klitz W, Fainboim L, Vullo C, Bodmer JG, Egea E, Navarrete C, Infante E, Alaez C, Olivo A, Debaz H, ET AL. 1997. Anthropology Report for Region LatinAmerica: Amerindian and admixed populations. In: Charron D (ed.) Genetic diversity of HLA: Functional and medical implications. Vol 1. Paris: EDK, pp. 337-345.

Ramon D, Scott I, Cox ST, Pesoa S, Vullo C, LitTLE AM and Madrigal JA. 2000. HLA-A*6817, identified in the Kolla Amerindians of North-West Argentina possesses a novel nucleotide substitution. Tiss Antigens 55: 453-454.

Ramos M, Postigo JM, Vilches C, Layrisse Z and López de CAstro JA. 1995a. Primary structure of a novel HLA-B39 allele (B*3909) from the Warao Indians of Venezuela. Further evidence for local HLA- 
B diversification in South America. Tiss Antigens 46: 401-404.

Ramos MD, Lalueza C, Girbau E, Pérez-Pérez A, Quevedo S, Turbón D and Estivil X. 1995b. Amplifying dinucleotide microsatellite loci from bone and tooth samples of up to 5000 years of age: More inconsistency than usefulness. Hum Genet 96: 205212.

Rangel-Villalobos H, Rivas F, SANDOVal L, Ibarra

B, García-Carvajal ZY, Cantú JM and Figuera LE. 2000. Genetic variation among four Mexican populations (Huichol, Purepecha, Tarahumara, and Mestizo) revealed by two VNTRs and four STRs. Hum Biol 72: 983-995.

Ribeiro-dos-Santos AKC, Santos SEB, Machado AL, Guapindaia V and Zago MA. 1996. Heterogeneity of mitochondrial DNA haplotypes in preColumbian natives of the Amazon region. Am J Phys Anthropol 101: 29-37.

Ribeiro-dos-Santos AKC, Santos SEB, Machado AL, Guapindaia V and Zago MA. 1997. Reply to Monsalve on "Mitochondrial DNA in ancient Amerindians", American Journal of Physical Anthropology (1997) 103: 423-425. Am J Phys Anthropol 103: 571.

Ribeiro-dos-Santos AKC, Guerreiro JF, SANTos SEB AND ZAGo MA. 2001. The split of the Arara population: Comparison of genetic drift and founder effect. Hum Hered 51: 79-84.

Rickards O, Martínez-Labarga C, Lum JK, De SteFANO GF AND CANN RL. 1999. mtDNA history of the Cayapa Amerinds of Ecuador: Detection of additional founding lineages for the Native American populations. Am J Hum Genet 65: 519-530.

Rivas F, Zhong Y, Olivares N, CERDA-Flores RM AND ChaKraborty R. 1997. Worldwide genetic diversity at the HLA-DQ A1 locus. Am J Hum Biol 9: 735749 .

Rodriguez-Delfin L, SANtos SEB and Zago MA. 1997. Diversity of the human Y chromosome of South American Amerindians: A comparison with Blacks, Whites, and Japanese from Brazil. Ann Hum Genet 61: 439-448.

Roewer L, Nagy M, Schmidt P, Epplen JT AND HerzoG-SchröDER G. 1993. Microsatellite and HLA class II oligonucleotide typing in a population of Yanomami Indians. In: PENA SDJ, Chakraborty R, EPplen JT AND JefFreys AJ (eds.) DNA fingerprinting: State of the science. Basel, Birkhäuser Verlag, pp. 221-230.

Rogan PK AND SALvo JJ. 1990. Molecular genetics of Pre-Columbian South American mummies. UCLA Symp Mol Cell Biol 122: 223-234.

Rogan PK AND SALvo JJ. 1994. High-fidelity amplification of ribosomal gene sequences from South American mummies. In: Herrmann B and Hummel $S$ (eds.) Ancient DNA. Berlin: Springer-Verlag, pp. 182-194.

Rothhammer F, Silva C, Callegari-JacQues SM, Llop E And Salzano FM. 1997. Gradients of HLA diversity in South American Indians. Ann Hum Biol 24: 197-208.

Roychoudhury AK AND Nei M. 1988. Human polymorphic genes. World distribution. Oxford: Oxford University Press.

Ruiz-Linares A, Nayar K, Goldstein DB, Hebert JM, Seielstad MT, Underhill PA, Lin AA, Feldman MW and CAvalli-Sforza LL. 1996. Geographic clustering of human Y-chromosome haplotypes. Ann Hum Genet 60: 401-408.

Ruiz-Linares A, Ortíz-Barrientos D, Figueroa M, Mesa N, Múnera JG, Bedoya G, Vélez ID, García LF, Pérez-Lezaun A, Bertranpetit J, FeldMAN MW AND GoldSTEIN DB. 1999. Microsatellites provide evidence for $Y$ chromosome diversity among the founders of the New World. Proc Natl Acad Sci USA 96: 6312-6317.

Ruiz Narvaez EA. 1998. Variación genética del cromosoma Y en las poblaciones amerindias de Costa Rica y Panamá. M.Sc. Dissertation, Universidad de Costa Rica, San José.

Rupert JL, Devine DV, Monsalve MV and HochaCHKA PW. 1999a. $\beta$-fibrinogen allele frequencies in Peruvian Quechua, a high-altitude native population. Am J Phys Anthropol 109: 181-186.

Rupert JL, Devine DV, Monsalve MV and HochaCHKA PW. 1999b. Angiotensin-converting enzyme (ACE) alleles in the Quechua, a high altitude South American native population. Ann Hum Biol 26: 375380 .

Rupert JL, Monsalve MV, Devine DV and HochaCHKA PW. 2000. Beta2-adrenergic receptor allele 
frequencies in the Quechua, a high altitude native population. Ann Hum Genet 64: 135-143.

Sala A, Penacino G and Corach D. 1998. Comparison of allele frequencies of eight STR loci from Argentinian Amerindian and European populations. Hum Biol 70: 937-947.

Sala A, Penacino G, Carnese FR and Corach D. 1999. Reference database of hypervariable genetic markers of Argentina: Application for molecular anthropology and forensic casework. Electrophoresis 20: 1733-1739.

Salamon H, Klitz W, Easteal S, Gao X, Erlich HA, Fernández-Viña M, Trachtenberg EA, Mc Weeney SK, Nelson MP and Thomson G. 1999. Evolution of HLA Class II molecules: Allelic and amino acid site variability across populations. Genetics 152: 393-400.

Salemi M, Lewis M, Egan JF, Hall WW, Desmyter I AND VANDAMme A-M. 1999. Different population dynamics of human $\mathrm{T}$ cell lymphotropic virus type II in intravenous drug users compared with endemically infected tribes. Proc Natl Acad Sci USA 96: 1325313258 .

Salzano FM and Callegari-Jacques SM. 1988. South American Indians. A case study in evolution. Oxford: Clarendon Press.

SAntos EJM. 1998. Os últimos 5000 anos de história ameríndia na Amazônia: Recente expansão, migração e deriva genética. Ph.D. Dissertation, Universidade Federal do Pará, Belém.

Santos EJM, Epplen JT, Epplen C and Guerreiro JF. 1998. Microsatellite evolution in the 5' STR of the HLA-F gene. Hum Evol 13: 57-64.

Santos FR, Pena SDJ and Tyler-Smith C. 1995a. PCR haplotypes for the human Y chromosome based on alphoid satellite DNA variants and heteroduplex analysis. Gene 165: 191-198.

SAntos FR, Hutz MH, Coimbra CEA Jr, Santos RV, Salzano FM and Pena SDJ. 1995b. Further evidence for the existence of a major founder Y chromosome haplotype in Amerindians. Braz J Genet 18 : 669-672.

Santos FR, Gerelsaikhan T, Munkhtuja B, OyunSUREN T, EpPlen JT AND PENA SDJ. 1996a. Geographic differences in the allele frequencies of the human Y-linked tetranucleotide polymorphism DYS19.
Hum Genet 97: 309-313.

Santos FR, Rodriguez-Delfin L, Pena SDJ, Moore J AND WeIss KM. 1996b. North and South Amerindians may have the same major founder Y chromosome haplotype. Am J Hum Genet 58: 1369-1370.

Santos FR, Bianchi NO And Pena SDJ. 1996c. Worldwide distribution of human Y-chromosome haplotypes. Genome Res 6: 601-611.

Santos FR, Pandya A, Tyler-Smith C, Pena SDJ, Schanfield M, Leonard WR, Osipova L, CrawFORD MH AND Mitchell RJ. 1999. The Central Siberian origin for Native American Y chromosomes. Am J Hum Genet 64: 619-628.

SANTOS M, Ward RH AND BARRAntes R. 1994. mtDNA variation in the Chibcha Amerindian Huetar from Costa Rica. Hum Biol 66: 963-977.

SANTos SEB. 1996. Ameríndios sul-americanos: Quatro haplogrupos de DNA mitocondrial, múltiplos haplótipos fundadores. Ph.D. Dissertation, University of São Paulo, Ribeirão Preto.

Satten GA, Flandres WD and Yang Q. 2001. Accounting for unmeasured population substructure in case-control studies of genetic association using a novel latent-class model. Am J Hum Genet 68: 466477.

Scacchi R, Corbo RM, Rickards O, Mantuano E, Guevara A and de Stefano GF. 1997. Apolipoprotein $\mathrm{B}$ and $\mathrm{E}$ genetic polymorphisms in the Cayapa Indians of Ecuador. Hum Biol 69: 375-382.

Schneider JA, ReEs DC, Liu Y-T ANd Clegg JB. 1998. Worldwide distribution of a common methylenetetrahydrofolate reductase mutation. Am J Hum Genet 62: 1258-1260.

Scott I, Dunn PPJ, Day S, Pesoa S, Little A-M, Madrigal JA and Vullo C. 1999. A novel HLA allele, HLA-B*5113, identified in the Kolla Amerindians of North-West Argentina. Tiss Antigens 53: 194197.

Scozzari R, Cruciani F, Santolamazza P, Sellitto D, Cole DEC, Rubin LA, Labuda D, Marini E, Succa V, Vona G and Torroni A. 1997a. mtDNA and $Y$ chromosome-specific polymorphisms in modern Ojibwa: Implications about the origin of their gene pool. Am J Hum Genet 60: 241-244.

Scozzari R, Cruciani F, Malaspina P, Santolamazza P, Ciminelli BM, Torroni A, Modiano 
D, Wallace DC, Kidd KK, Olckers A, Moral P, Terrenato L, Akar N, Qamar R, Mansoor A, Mehdi SQ, Meloni G, Vona G, Cole DeC, Cai W AND Novelletto A. 1997b. Differential structuring of human populations for homologous $\mathrm{X}$ and $\mathrm{Y}$ microsatellite loci. Am J Hum Genet 61: 719-733.

Selvakumar A, Granja CB, Salazar M, Alosco SM, Yunis EJ AND DU Pont B. 1995. A novel subtype of A2 $(A * 0217)$ isolated from the South American Indian B-cell line AMALA. Tiss Antigens 45: 343347.

Shen P, Wang F, Underhill PA, Franco C, Yang W-H, Roxas A, Sung R, Lin AA, Hyman RW, Vollrath D, Davis RW, Cavalli-Sforza LL and Oefner PJ. 2000. Population genetic implications from sequence variation in four Y chromosome genes. Proc Natl Acad Sci USA 97: 7354-7359.

Sherry ST AND BATzer MA. 1997. Modeling human evolution - to tree or not to tree? Genome Res 7: 947-949.

Shields GF, Schmiechen AM, Frazier BL, RedD A, Voevoda MI, Reed JK AND WARd RH. 1993. mtDNA sequences suggest a recent evolutionary divergence for Beringian and northern North American populations. Am J Hum Genet 53: 549-562.

Shimizu K, Hashimoto T, Harihara S, Tajima K, SonODA S ANDZANINOVIC V. 2001. $\beta$-globin gene haplotype characteristics of Colombian Amerinds in South America. Hum Hered 51: 54-63.

Simon D, Bandinelli E ANd Roisenberg I. 2000. Von Willebrand factor gene polymorphisms in three Brazilian ethnic groups. Hum Biol 72: 1055-1063.

Smith DG, Malhi RS, Eshleman J, LoRenz JG AND Kaestle FA. 1999. Distribution of mtDNA haplogroup X among native North Americans. Am J Phys Anthropol 110: 271-284.

Sotomaior VS, Faucz FR, Schfhauser C, JanzenDück M, Boldt ABW ANd Petzl-Erler ML. 1998. HLA-DQA1 and HLA-DQB1 alleles and haplotypes in two Brazilian Indian tribes: Evidence of conservative evolution of HLA-DQ. Hum Biol 70: 789-797.

Stephens JC, Reich DE, Goldstein DB, Shin HD, Smith MW, Carrington M, Winkler C, Huttley GA, Allikmets R, Schriml L, Gerrard B, Malasky M, Ramos MD, Morlot S, Tzetis M,
Oddoux C, di Giovine FS, Nasioulas G, Chandler D, Aseev M, Hanson M, Kalaydjieva L, Glavac D, Gasparini P, Kanavakis E, Claustres M, Kambouris M, Ostrer H, Duff G, Varanov V, Sibul H, Metspalv A, Goldman D, Martin N, Duffy D, SchmidtKe J, Estivil X, O'Brien SJ AND DEAN M. 1998. Dating the origin of the CCR5- $\triangle 32$ AIDS-resistance allele by the coalescence of haplotypes. Am J Hum Genet 62: 1507-1515.

Stone AC And Stoneking M. 1993. Ancient DNA from a pre-Columbian Amerindian population. Am J Phys Anthropol 92: 463-471.

Stone AC And Stoneking M. 1998. mtDNA analysis of a prehistoric Oneota population: Implications for the peopling of the New World. Am J Hum Genet 62: 1153-1170.

Stone AC and Stoneking M. 1999. Analysis of ancient DNA from a prehistoric Amerindian cemetery. Phil Trans R Soc London 354: 153-159.

Stoneking M, Fontius JJ, Clifford SL, Soodyall H, Arcot SS, Saha N, Jenkins T, Tahir MA, DeininGER PL AND BATzer MA. 1997. Alu insertion polymorphisms and human evolution: Evidence for a larger population size in Africa. Genome Res 7: 1061-1071.

Su B, Jin L, Hu F, Xiao J, Luo J, Lu D, Zhang W, Chu J, Du R, Geng Z, Qiu X, Xue J, Tan J, O’Brien SJ AND Chakraborty R. 1999a. Distribution of two HIV-1-resistant polymorphisms (SDF-3'A and CCR2-64I) in East Asian and world populations and its implication in AIDS epidemiology. Am J Hum Genet 65: 1047-1053.

Su B, Xiao J, Underhill P, Deka R, Zhang W, Akey J, Huang W, Shen DI, Lu D, Luo J, Chu J, Tan J, Shen P, Davis R, Cavalli-Sforza L, ChakraborTy R, Xiong M, Du R, Oefner P, Chen Z And Jin L. 1999b. Y-chromosome evidence for a northward migration of modern humans into Eastern Asia during the last ice age. Am J Hum Genet 65: 1718-1724.

Tarazona-Santos E, Carvalho-Silva DR, Pettener D, Luiselli D, DE Stefano GF, Labarga CM, Rickards O, Tyler-Smith C, Pena SDJ and SANTOS FR. 2001. Genetic differentiation in South Amerindians is related to environmental and cultural diversity: Evidence from the Y chromosome. Am J Hum Genet 68: 1485-1496. 
Theiler GC, Marcos YC, Kolkowski E, Lindel N, Capucchio M, Barrionuevo P, Carnese FR and SATz ML. 1996. Complete sequence of a new HLAB35 allele found in a tribe of Mapuche Indians in the south of Argentina. Immunogenetics 43: 398-399.

Thomas R, Zischler H, Pä̈̈вo S And Stoneking M. 1996. Novel mitochondrial DNA insertion polymorphism and its usefulness for human population studies. Hum Biol 68: 847-854.

Tills D, Kopeć AC and Tills RE. 1983. The distribution of the human blood groups and other polymorphisms. Supplement 1. Oxford: Oxford University Press.

Tishkoff SA, RuAno G, KidD JR And KIDD KK. 1996a. Distribution and frequency of a polymorphic Alu insertion at the plasminogen activator locus in humans. Hum Genet 97: 759-764.

Tishkoff SA, Dietzsch E, Speed W, Pakstis AJ, Kidd JR, Cheung K, Bonné-Tamir B, SantachiaraBenerecetti aS, Moral P, Krings M, Pä̈̈вo S, Watson E, Risch N, Jenkins T and Kidd KK. 1996b. Global patterns of linkage disequilibrium at the CD4 locus and modern human origins. Science 271: 1380-1387.

Tishroff SA, Goldman A, Calafell F, Speed WC, Deinard AS, Bonné-Tamir B, Kidd JR, Pakstis AJ, JENKIns T AND KIDD KK. 1998. A global haplotype analysis of the myotonic dystrophy locus: Implications for the evolution of modern humans and for the origin of myotonic dystrophy mutations. Am J Hum Genet 62: 1389-1402.

Tishkoff SA, Pakstis AJ, Stoneking M, Kidd JR, Destro-Bisol G, Sanjantila A, LU RB, Deinard AS, Sirugo G, Jenkins T, Kidd KK and Clark AG. 2000. Short tandem-repeat polymorphism/Alu haplotype variation at the PLAT locus: Implications for modern human origins. Am J Hum Genet 67: 901-925.

Titus-Trachtenberg EA, Rickards O, de Stefano GF AND ERLich HA. 1994. Analysis of HLA class II haplotypes in the Cayapa Indians of Ecuador: A novel DRB1 allele reveals evidence for convergent evolution and balancing selection at position 86. Am J Hum Genet 55: 160-167.

Torroni A, Schurr TG, YAng C-C, Szathmary EJE, Williams RC, Schanfield MS, Troup GA, KNOWLer WC, LaWrence DN, Weiss KM and Wallace
DC. 1992. Native American mitochondrial DNA analysis indicates that the Amerind and the Nadene populations were founded by two independent migrations. Genetics 130: 153-162.

Torroni A, Schurr TG, Cabell MF, Brown MD, Neel JV, Larsen M, Smith DG, Vullo CM And WalLACE DC. 1993. Asian affinities and continental radiation of the four founding Native American mtDNAs. Am J Hum Genet 53: 563-590.

Torroni A, Chen Y-S, Semino O, Santachiara-BeneCERETTi AS, SCOTT CR, LotT MT, Winter M AND WALlaCE DC. 1994. mtDNA and Y-chromosome polymorphisms in four Native American populations from southern Mexico. Am J Hum Genet 54: 303318.

Trachtenberg EA, Erlich HA, Rickards O, De SteFANO GF AND KLITZ W. 1995. HLA class II linkage disequilibrium and haplotype evolution in the Cayapa Indians of Ecuador. Am J Hum Genet 57: 415-424.

Trachtenberg EA, Keyeux G, Bernal Je, Rhodas MC AND ERLich HA. 1996. Results of expedicion humana. I. Analysis of HLA class II (DRB1-DQA1DQB1-DPB1) alleles and DR-DQ haplotypes in nine Amerindian populations from Colombia. Tiss Antigens 48: 174-181.

Trachtenberg EA, Keyeux G, Bernal J and ErLICH HA. 1998. Colombian Amerindian normal. In: GJertson DW AND TARASAKI PI (eds.) HLA 1998. Lenexa: American Society of Histocompatibility and Immunogenetics, pp. 226.

Underhill PA, Jin L, ZEMAns R, OEFner PJ AND Cavalli-Sforza LL. 1996. A pre-Columbian Y chromosome-specific transition and its implications for human evolutionary history. Proc Natl Acad Sci USA 93: 196-200.

Underhill PA, Jin L, Lin AA, Mehdi SQ, Jenkins T, Vollrath D, Davis RW, Cavalli-Sforza LL AND Oefner PJ. 1997. Detection of numerous Y chromosome biallelic polymorphisms by denaturing high-performance liquid chromatography. Genome Res 7: 996-1005.

Urbanek M, Goldman D and Long JC. 1996. The apportionment of dinucleotide repeat diversity in Native Americans and Europeans: A new approach to measuring gene identity reveals asymmetric patterns of divergence. Mol Biol Evol 13: 943-953. 
Valdes AM, McWeeney SK, Meyer D, Nelson MP And Thomson G. 1999. Locus and population specific evolution in HLA class II genes. Ann Hum Genet 63: 27-43.

Vallinoto ACR, Cayres-Vallinoto IMV, Zago MA, SANTOS SEB AND GuERrEIRo JF. 1998. D1S80 polymorphism in Amerindians from the Amazon Region of Brazil. Hum Biol 70: 507-516.

Vallinoto ACR, Cayres-Vallinoto IMV, Ribeiro dos Santos AKC, Zago MA, Santos SEB And GuerREIRO JF. 1999. Heterogeneity of Y chromosome markers among Brazilian Amerindians. Am J Hum Biol 11: 481-487.

Vargas-Alarcón G, Martinez-Laso J, Granados J, Diaz-Campos N, Alvarez M, Gomez-Casado E, Alcocer-Varela J and Arnaiz-Villena A. 1996a. Description of a novel HLA-B35 $(B * 3514)$ allele found in a Mexican family of Nahua Aztec descent. Hum Immunol 45: 148-151.

Vargas-Alarcón G, Alvarez M, Martinez-Laso J, Granados J, Diaz-Campos N, Gomez-Casado E, Alcocer-Varela J and Arnaiz-Villena A. 1996b. A new HLA-B35 ( $B * 3516)$ allele found in a Mexican of Nahua (Aztec) descent. Immunogenetics 43: 244-245.

Vargas-Alarcón G, Martinez-Laso J, GomeZ-Casado E, Granados J, Diaz-Campos N, Varela P, Alvarez M and Arnaiz-Villena A. 1996c. A novel HLA-B35 $(B * 3517)$ allele found in a Mexican of Otomi descent. Tiss Antigens 47: 547-550.

Vargas-Alarcón G, Gomez-Casado E, MartínezLaso J, Granados J, Layrisse Z, Alegre R and Arnaiz-Villena A. 1997. Differences in intron 2 sequences between B*39061 and B*39062 in Amerindians: Comparison with those of B*3901, B*5101, and B*52012 alleles. Immunogenetics 45: 436-439.

Vona G, Calo CM, Mameli GE, Marini E, Morelli L, Succa V, Casula S and Ristaldi MS. 1996. Variability of the CD4 and F13A1 short tandem repeats in Corsicans, Sardinians and Piaroa Indians. Gene Geogr 10: 51-63.

Vullo CM, Delfino L, Angelini G and Ferrara GB. 1992. HLA polymorphism in a Mataco South American Indian tribe: Serology of class I and II antigens. Molecular analysis of class II polymorphic variants.
Hum Immunol 35: 209-214.

Wall TL, Garcia-Andrade C, Thomasson HR, Carr LG AND EhLERs CL. 1997. Alcohol dehydrogenase polymorphisms in Native Americans: Identification of the ADH2*3 allele. Alcohol and Alcoholism 32: 129-132.

Wallace DC, Garrison K And KnOWler WC. 1985. Dramatic founder effects in Amerindian mitochondrial DNAs. Am J Phys Anthropol 68: 149-155.

Ward RH, Frazier BL, Dew-Jager K AND PäÄвo S. 1991. Extensive mitochondrial diversity within a single Amerindian tribe. Proc Natl Acad Sci USA 88: 8720-8724.

Ward RH, Salzano FM, Bonatto SL, Hutz MH, Coimbra CEA Jr and Santos RV. 1996. Mitochondrial DNA polymorphism in three Brazilian Indian tribes. Am J Hum Biol 8: 317-323.

Watkins DI, McAdam SN, LiU X, Strang CR, Milford EL, Levine CG, Garber TL, Dogon AL, Lord CI, Ghim SH, Troup GM, Hughes AL and Letvin NL. 1992. New recombinant HLA-B alleles in a tribe of South American Amerindians indicate rapid evolution of MHC class I loci. Nature 357: 329-333.

WeinberG W. 1908. Über den Nachweis der Vererbung beim Menschen. Jahreshefte Verein f vaterl Naturk in Wurttemberg 64: 368-382.

Yagüe J, Ramos M, Vázquez J, Marina A, Albar JP ANd López de Castro JA. 1999. The South Amerindian allotype HLA-B*3909 has the largest known similarity in peptide specificity and common natural ligands with HLA-B27. Tiss Antigens 53: 227-236.

Yagüe J, Ramos M, Ogueta S, VÁzQuez J and LóPeZ de Castro JA. 2000. Peptide specificity of the Amerindian B*3905 allotype: Molecular insight into selection mechanisms driving HLA class I evolution in indigenous populations of the Americas. Tiss Antigens 56: 385-391.

York DS, Blum VM, Low JA, Rowold DJ, Puzyrev V, Saliukov V, Odinokova O and Herrera RJ. 1999. Phylogenetic signals from point mutations and polymorphic Alu insertions. Genetica 107: 163-170.

Yunis JJ, Ossa H, Salazar M, Delgado MB, Deulofeut R, DE La Hoz A, Bing DH, Ramos O, Yunis EJ AND YUnIS EJ. 1994. Major histocompatibility complex class II alleles and haplotypes and blood 
groups of four Amerindian tribes of northern Colombia. Hum Immunol 44: 248-258.

Zago MA, Silva WA Jr, Tavella MH, Santos SEB, Guerreiro JF AND FigueIredo MS. 1996. Interpopulational and intrapopulational genetic diversity of Amerindians as revealed by six variable number of tandem repeats. Hum Hered 46: 274-289.

Zerjal T, Dashnyam B, Pandya A, Kayser M, Roewer L, Santos FR, Schiefenhövel W, Fretwell N, Jobling MA, Harihara S, Shimizu K, Semjidmaa D, Sajantila A, Salo P, Crawford MH, Ginter EK, Evgrafov OV and Tyler-Smith C. 1997. Genetic relationships of Asians and northern Europeans, revealed by Y-chromosomal DNA analysis. Am J Hum Genet 60: 1174-1183.

Zerjal T, Pandya A, Santos FR, Adhikari R, Tarazona E, Kayser M, Evgrafov O, Singh L, Thangaraj K, Destro-Bisol G, Thomas MG, Qamar R, Mehdi SQ, Rosser ZM, Hurles ME, Jobling MA AND Tyler-Smith C. 1999. The use of Y chromosomal DNA variation to investigate population history. Recent male spread in Asia and Europe. In: PAPIHA SS, Deka R and Chakraborty R (eds.) Genomic diversity: Applications in human population genetics. New York, Kluwer/Plenum, pp. 91-101.
Zhao W, Fernández-Viña MA, Lazaro AM, Araujo HA, Miller S and Stastny P. 1996. Full cDNA of a novel HLA-B39 subtype, B*39061. Tiss Antigens 47: 435-437.

Zhivotovsky LA, Bennett L, Bowcock AM AND Feldman MW. 2000. Human population expansion and microsatellite variation. Mol Biol Evol 17: $757-$ 767.

Zietkiewicz E, Yotova V, Jarnik M, Korab-LasKowska M, Kidd KK, Modiano D, Scozzari R, Stoneking M, Tishroff S, Batzer M and Labuda D. 1997. Nuclear DNA diversity in worldwide distributed human populations. Gene 205: 161-171.

Zietkiewicz E, Yotova V, Jarnik M, Korab-LasKowsKa M, KIDD KK, Modiano D, Scozzari R, Stoneking M, Tishroff S, Batzer M And Labuda D. 1998. Genetic structure of the ancestral population of modern humans. J Mol Evol 47: 146-155. 